\title{
THE NURSING PRESENCE IN GENERAL PRACTICE: REVEALING DIMENSIONS OF DAY-TO-DAY EXPERIENCE OF PRACTICE NURSES IN NEW ZEALAND
}

by

Katrina Fyers

A thesis submitted to the Victoria University of Wellington in partial fulfilment of the requirements for the degree of Master of Arts (Applied) in Nursing

Victoria University of Wellington 


\section{Table of Contents}

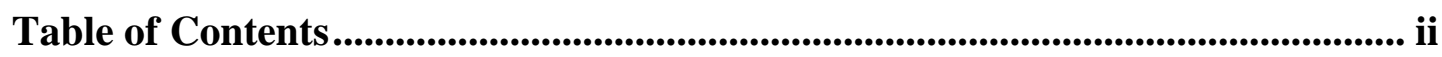

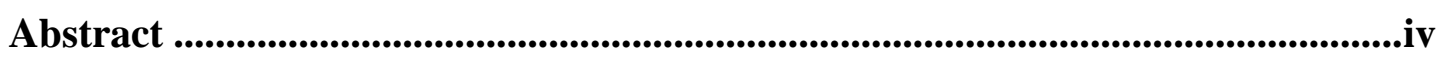

Acknowledgements .........................................................................................................................v

Chapter One: Study aim and rationale ............................................................................1

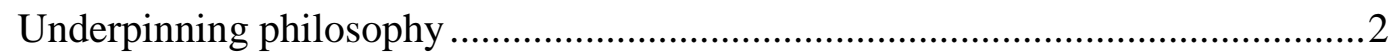

The emergence of the primary health care nurse .............................................. 3

Chapter Two: Professional and personal contexts ..............................................6

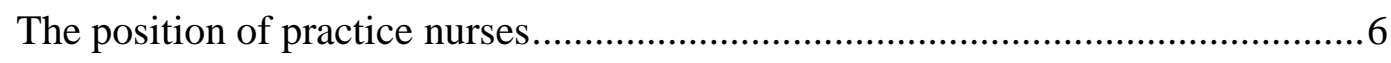

Personal context and positioning ............................................................... 10

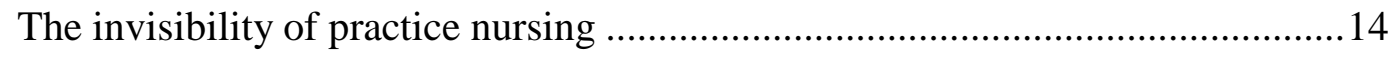

Chapter Three: Literature review ...............................................................................17

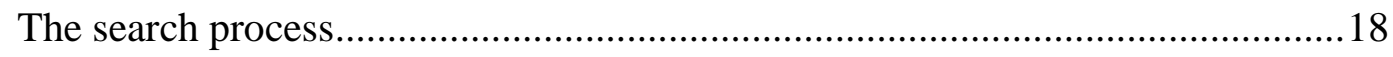

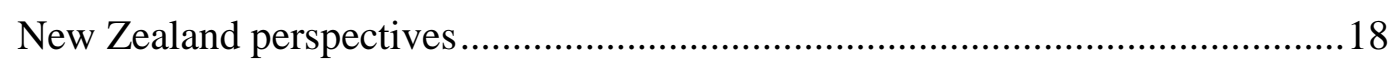

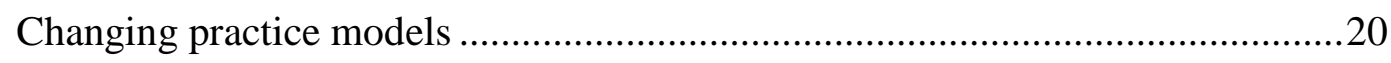

The possibilities of the practice nurse role ........................................................21

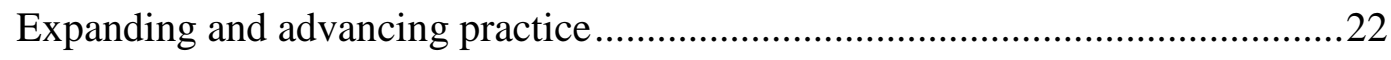

Chapter Four: Methodology, Method and Design......................................................27

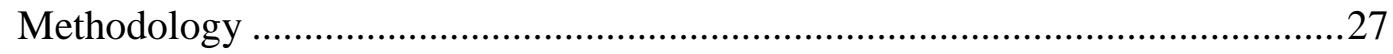

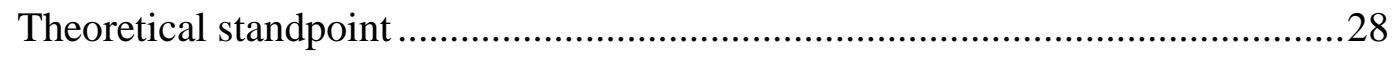

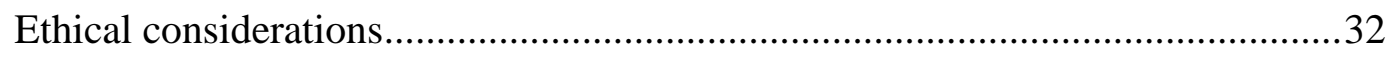

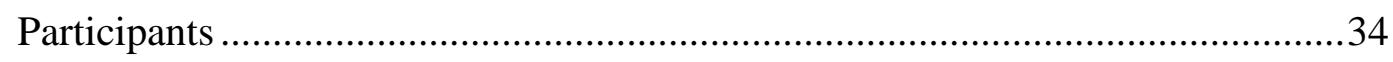

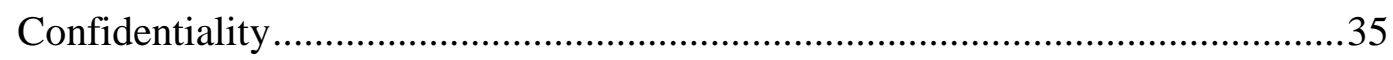

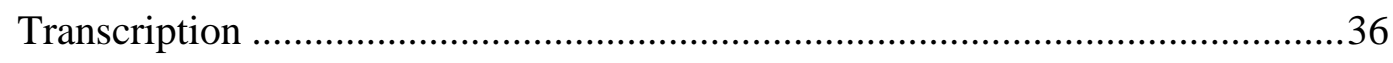

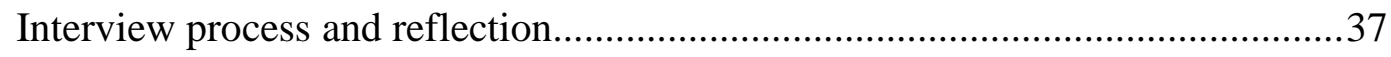

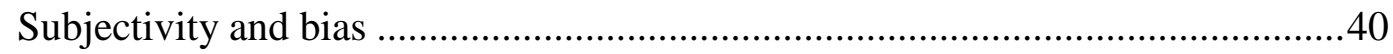

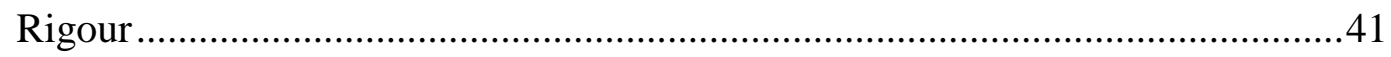

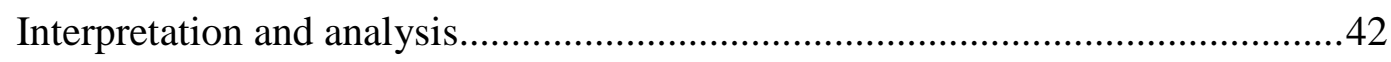

Chapter Five: Research findings - Dimensions of practice ......................................47

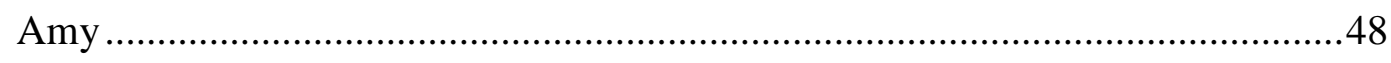

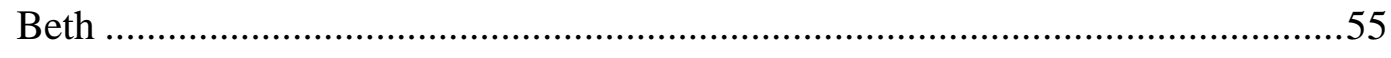

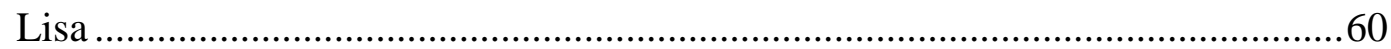


Molly

Penny

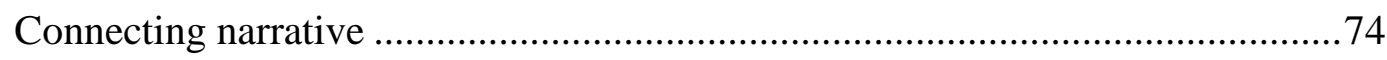

Chapter Six: Discussion and final conclusions........................................................77

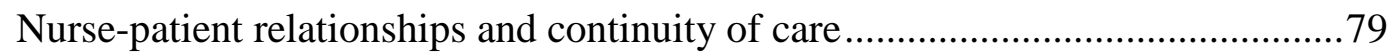

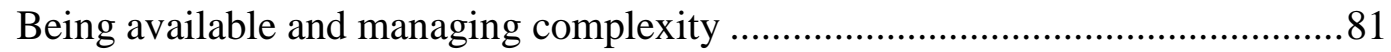

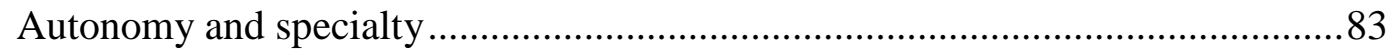

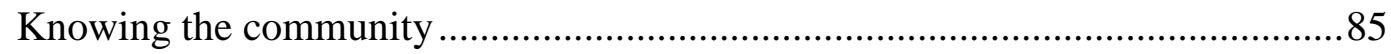

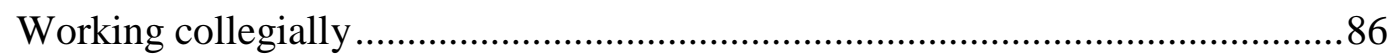

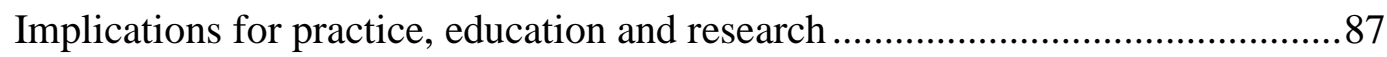

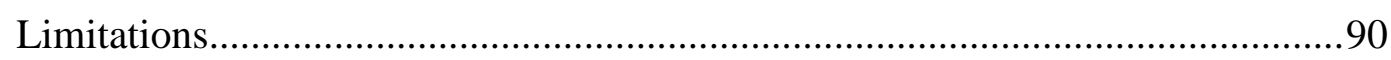

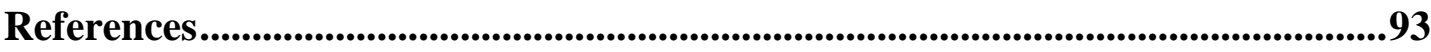

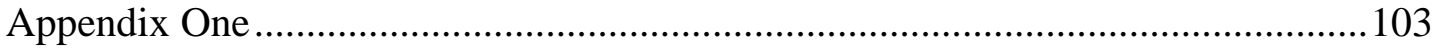

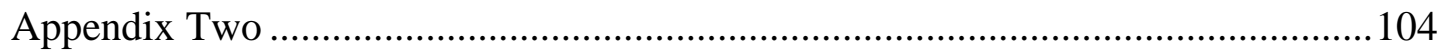

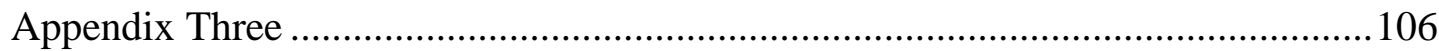

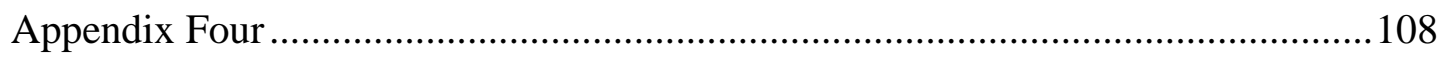

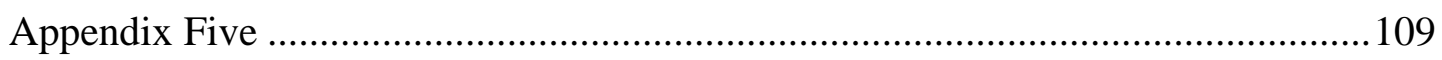




\begin{abstract}
This study makes visible and gives value to the day-to-day experience of practice nurses who work in New Zealand general practices. Nursing leaders internationally and locally have highlighted the importance of the Primary Health Care nurse to improving health outcomes, addressing inequalities and implementing new models of care. As one of the largest groups of Primary Health Care nurses, practice nurses have a significant part to play. There is however, no consensus and limited research related to the day-to-day experience of practice nurses. Therefore, the nature, extent, and contribution of nursing in general practice may be overlooked or misunderstood. Furthermore as an autonomous self-regulating profession, nursing has a responsibility to the public to provide understanding of nursing in the present and in the future, particularly when this relates to the care of families and the structure of health systems.
\end{abstract}

Located within the qualitative research paradigm and utilising a narrative inquiry methodology, this study applies a 'supportive voice' to highlight the experience of five practice nurses, and in the process makes visible the dimensions of nursing work in New Zealand general practices. The five constructed narratives particularly draw attention to the complex nature of nursing work that practice nurses engage in daily, the importance of nursepatient relationships and continuity of care and the significance of autonomous and specialty aspects of nursing practice. Ultimately, the value of the practice nurse in the day-to-day operation of general practice is brought to the fore.

Keywords: primary health nursing, general practice, practice nursing, nursing work, narrative inquiry 


\section{Acknowledgements}

This thesis would not have been completed without the contribution and support of a number of people. Firstly, I acknowledge and thank the five practice nurses who generously gave up their time and shared their experiences with me.

Heartfelt thanks to my supervisor Dr Jo Ann Walton, for her wise words, critical feedback, openness and enthusiasm that kept me going at difficult times.

Special thanks also to my colleague and friend Hilary for her understanding and support and to my good friends Liz and Mary - thanks for the walks and talks over the last eighteen months. I would also like to acknowledge the support of my nursing education colleagues who shared their experiences of research and writing.

To my mother Helen, my thanks for constant encouragement and the allimportant proofreading and to my children Andrew, Mark, Kirsten and Anna - I have appreciated your patience and understanding, especially when I have been 'unavailable'.

Finally, this thesis would not have been completed without the steadfast love and continuous support of my husband Clif.

This thesis is dedicated to the memory of Marion Witt, colleague and practice nurse - who was indeed 'a worthy nurse'. 


\title{
Chapter One: Study aim and rationale
}

\begin{abstract}
"The job at hand for nurses is to help the public construct an authentic meaning for the word nurse that conveys the richness, uniqueness and indispensability of nursing across the spectrum of nursing work. This means not repudiating caring or misconstruing it as simple intuition or as something commonplace, but deepening the public comprehension of caring as a complex, skilled and inherent part of nursing that is essential to patient care" (Buresh \& Gordon, 2000, p. 17).
\end{abstract}

This research project seeks to make visible and give value to the day-to-day experience of practice nurses ${ }^{1}$ who work in New Zealand general practices. My experience as a practice nurse and educator in primary health care has led to my interest in this area. One of the most consistent comments I hear is that practice nurses feel that their work is at times unrecognised, undervalued and that their voice is unheard. At times, I have experienced similar feelings and frustrations in response to medical and commercial discourses whilst working as a practice nurse. Practice nurse work incorporates both generalist and specialist knowledge and skill aligned to the needs of a diverse populations and communities. Despite this, historical and traditional stereotypes and expectations persist.

Practice nurses are understood to be in an ideal position to address the identified goals of primary health care and work collaboratively with general practitioners, (MOH, 2003). Nevertheless, regardless of increased expectations on nursing within this context, there is no consensus about what practice nurses do and the nature, extent and contribution of nursing in general practice continues to be overlooked and misunderstood both inside and outside nursing circles.

\footnotetext{
${ }^{1}$ For the purposes of this project I have chosen to use the full title 'practice nurse' instead of $\mathrm{PN}$ to differentiate it from other abbreviations.
} 


\section{Underpinning philosophy}

Primary Health Care (PHC) has been a major feature of global health policy since 1978 when a number of nations signed the Alma Ata declaration. The impetus for this significant policy shift arose from concerns that, despite increasing medical knowledge, technology and expertise, levels of disease and ill health were not improving. In effect, the promise of a modern biomedical world that was able to cure and treat had not lived up to expectations.

Additionally there was, and continues to be, growing recognition that health is determined by a range of complex social, economic, ecological and political factors (Dew \& Kirkman, 2002; McMurray, 2003).

In essence the Declaration of Alma Ata (WHO, 1978) promoted "the development of new solutions and directions in public health" (McMurray, p. 17) and defined PHC as a fundamental human right for the $21^{\text {st }}$ century. Further World Health Organization declarations such as the Ottawa Charter (WHO, 1986) and the Jakarta Declaration (WHO, 1997) have continued to stress the importance of approaches that address issues of health inequity, access to affordable health care and community development. However, regardless of this international commitment, in general, countries have been slow to take up the challenge and reorient health services. In part, this reluctance may be due to dominant medical paradigms and the Western notion the PHC only has a place in developing countries (Macdonald, 2004).

In the year 2000, in the face of health challenges such as global epidemics, an aging population and the increasing number of people with chronic conditions, the implementation of a PHC structure that encompasses preventative, accessible care appropriate to specific population needs has become imperative. Critical to this goal, is an approach that encompasses "the need for community participation in decision making, the importance of equity, an emphasis on health promotion, a multi-sectorial approach to health problems and the adoption and use of appropriate technology" (Green, 2004, p. 290). 
In the New Zealand health environment, the Primary Health Care Strategy (PHCS) launched in 2001, resonated with current international trends and focused on the principles of primary health care - those of community development, improved access to health care, well-educated health teams, participation of populations in policy and development, cost effective preventive care and health promotion (King, 2001). Additionally this strategy sought to address social and economic inequalities brought on by various historical injustices, various government policies and economic recession. Inequities have and continue to affect Māori and during the 1990s, primary health care was out of reach for many. Some of this inequity can be placed at the door of general practice and the nature of fee-for-service structures. As Barrett and Barrett (2005, p. 187) state, "primary care was essentially a private service, historically resistant to change, and lacking the organisational structures necessary for contracting". Therefore, general practitioners (GPs) have been disinclined to enter into collaborative relationships with the community and non-governmental or governmental organisations in order to implement primary health care initiatives.

\section{The emergence of the primary health care nurse}

The PHCS proposed the development of Primary Health Organisations (PHOs). These organisations are locally governed, and required to work in collaboration with and be accountable to larger District Health Boards (DHBs). PHC funding is channelled through PHOs and a large percentage of this money is then transferred to general practices via a model of capitation (or a funding per head formula that factors in variables such as age, gender, ethnicity and deprivation levels). The aim of funding individual health care based on population health need is to ensure that primary medical care is more affordable and that services develop within the general practice context to meet particular needs. For example, the range of services now encompasses lower costs for a visit to the general practitioner; reduced prescription fees or improved access to services ordinarily only found in a hospital setting (King, 2001). 
It is in this environment that the primary health care nurse has been signalled as vital to the successful implementation of effective primary health care. In addition, an important aim of capitation funding was that by removing the feefor-service model of payment previously linked only to GP work, there was opportunity to enhance nursing roles and provide expanded services such as chronic disease management and health education; this would also release the GP to manage complex situations (Crampton, Sutton \& Foley, 2002). Furthermore, in order to address the inequalities faced by New Zealand populations, particularly Māori, Pacific and low socio-economic groups, nursing must lift its gaze beyond the treatment, medicalisation and commodifcation of health (College of Nurses Aotearoa, 2001).

This means that the nursing world must embrace the possibilities of the PHC nurse and develop a shared vision to work towards true PHC. This is even more imperative as health services move away from institutions and into the community (Carr, Bell, Pearson \& Watson, 2001). As Besner (2004) believes nurses are obliged to be involved in the implementation of PHC to both "revitalise the nursing workforce" (p. 351) and, in order to enact historical nursing values that focus on population health in relation to social determinants. However, as Kendall and Bryar (2003) observe, while "the role of the PHC nurse has been repeatedly affirmed in national and international policy" (p. 95), evidence in support of this premise is less apparent.

Within this exciting but complex environment and in the face of the issues discussed previously this thesis provides a view of nursing in general practice set against the context of the primary health care strategy. Chapter Two explores the professional nature of the practice nurse and my own personal interest in this study. Chapter Three presents a literature review of international and national research and defines the research gap. Chapter Four presents the research design and underpinning methodology. In Chapter Five the first part of the findings is presented in the narratives of five practice nurses. Chapter Six then puts forward further discussion and implications for practice, research and education followed by final conclusions and reflections. 
In addition each chapter begins with a quotation that reflects the ideas presented. 


\section{Chapter Two: Professional and personal contexts}

"The handmaiden stereotype may be less mythical than nursing would like to acknowledge" (Darbyshire, 2006, p. 53)

\section{The position of practice nurses}

In New Zealand, practice nurses are one of the largest groups of PHC nurses (MOH, 2003). Other groups of PHC nurses include plunket nurses, district nurses, public health nurses and others who work in community contexts such as marae based clinics or accident and medical centres. Generally practice nurses are employed by general practitioners although since 2001 a number of different employment models have developed, where a local iwi provider or rural trust employs both nurses and doctors on salaries (Barrett \& Barrett, 2004). Prior to 2001, the practice nurse salary was subsidised at a rate of 33 $40 \%$ by the New Zealand government. However, this funding has now been absorbed into capitation payments (as discussed previously).

Nowadays it is unclear how much of the capitation funding is for nursing work or nursing development and consequently practice nursing work has become somewhat invisible in funding schemes (Minto, 2004). Furthermore, until recently practice nurses have failed to reach pay parity with their DHB employed colleagues due to private employment arrangements. After lengthy negotiations with general practitioners this inequity has now been rectified with the signing of a multi employer collective aggreement (MECA). Whether or not this PHC MECA will be able to keep up with increasing pay rates in secondary care is uncertain and the nature and value of practice nurse work remains a point of contention.

Interestingly in the past, most nursing leadership has developed within DHBs and often configured to meet the needs of DHB employed nurses. As a result, for practice nurses, coordinated clinical support, education, and development of nursing roles have been dependent upon the goodwill of their employers or various ad hoc education or peer support initiatives. Practice nurses often 
commit their own time for professional development and peer support due to their inability to leave the workplace without placing pressure on other nursing staff and a lack of locum nurses. Recently this has begun to change with increased practice nurse leadership and political voice (McKinlay, 2006) and within some PHO structures and DHBs.

As stated previously many practice nurses feel undervalued and misunderstood and to some extent this has surfaced in response to new roles and drivers signalled within the PHCS and the development of PHOs (O'Connor, 2003). In my experience, with the finalising of the MECA the cost of nursing has been blamed for rising patient fees. Subsequently nurses have been placed in a position where they have to justify their existence by demonstrating that they are adding value on a day-to-day basis.

Since 1942 New Zealand has, in essence, had a dual system of health publicly funded secondary / tertiary services and "largely privately provided primary medical care services" (Crampton, 1999, p. 203) known as general practice. This is despite successive governments attempting to restructure health in the primary care sector and meet the needs of specific populations in an efficient and equitable way. For example in 1986 specific subsidies for children were introduced, followed by the introduction of the high user health card and community services cards targeted at the chronically ill and lowincome families in 1992. Again in 1993 in another attempt to regulate the sector all GPs were required to enter into a contract with a funding authority. Furthermore as population health approaches change it is unlikely that this will change, especially as nurse practitioner and mobile nursing roles develop.

Throughout the development of primary medical services in New Zealand, general practitioners have directly employed practice nurses privately. However the role was undefined and often included receptionist duties (Docherty, 1996; McKinlay, 2006). A more explicit practice nurse role developed in 1970 when the government, in line with its commitment to public health, provided a subsidy for nurses employed in rural practices. In 
1974 the subsidy increased to $100 \%$ and subsequently there was a greater number of practice nurses working alongside general practitioners in both rural and urban settings, but still often carrying out receptionist duties (Docherty). In 1983 and in 1991 the scheme was again updated to ensure that nurses were carrying out mainly nursing duties. Interestingly, at this time a GP was considered to require 30 hours of nursing work to support his / her full time practice.

Currently practice nurses in New Zealand continue to work alongside general practitioners who serve a particular population and community defined by both location and formal practice enrolment. Prior to 2001 practice nurses were already working in expanded roles and supporting general practitioners in varied ways such as after hours care, home visiting, occupational health, nurse led clinics and emergency care. This was particularly evident in rural or underserved areas (Docherty, 1996).

Since this time, and in part due to governmental direction around the subsidy scheme practice nursing has evolved to encompass standards of practice, position descriptions, a college journal and a professional development and recognition portfolio programme administered by the College of Practice Nurses, who act as a subdivision of the New Zealand Nurses' Organisation. In addition, practice nurses have become one of the largest groups of nurses working in the community (Docherty, 1996; McKinlay, 2006). However, the method of subsidy changed in late 2001 with the introduction of capitation funding. In essence, the practice nurse subsidy although still in place was part of capitation funding and no longer explicit or monitored by the Ministry of Health as it had been over the past 30 years. Moreover with the implementation of the PHC strategy the practice nurse role has expanded at a fast pace (McKinlay) and expectations of practice nurses are high (Lowry, 2005; Hodgson, 2006).

In 2003, the Health Practitioners Competency Assurance Act replaced the Nurses Act of 1977 and defined nursing with scopes of practice. Within this 
context, the role of the practice nurse now links clearly to that of the PHC nurse, defined by the Expert Advisory Group on Primary Health Care Nursing (2003) as:

Registered nurses with knowledge and expertise in primary health care practice. Primary health care nurses work autonomously and collaboratively to promote, improve, maintain and restore health. Primary health care nursing encompasses population health, health promotion, disease prevention, wellness care, first-point-ofcontact care and disease management across the lifespan. The setting and the ethnic and cultural grouping of the people determine models of practice. Partnership with people, individuals, whānau, communities and populations to achieve the shared goal of health for all, is central to primary health care nursing.

In addition, the College of Practice Nurses is currently proposing to change its name to the College of Primary Health Care Nurses. This is partly to reinforce the premise that practice nurses are in an ideal position to work as part of the general practice team to address issues such as illness prevention and health promotion, community capacity building and reduce inequalities amongst population groups.

In the PHC environment, change and innovation have been accompanied by uncertainty, particularly in nursing (Sibbald, 2003). In New Zealand despite scoping exercises that state that practice nurses work at the level of their secondary care colleagues (Kai Tiaki, 2006) there is still a perception in general practice and the community that practice nurses work as doctor's assistants and are not really 'nurses'. Traditional roles and structures, the 'treat' and 'cure' constructs that surround general practice contexts, contribute to this misconception alongside the wide recognition given to new roles within general practice. 


\section{Personal context and positioning}

I first began practice nursing in 1982 as the sole nurse, employed by a general practitioner (GP), in a small rural town. At that time, there was no nursing support for the role and the only collegial relationships that I had were with the local district nurses (DN) or those nurses with whom I had trained. I saw every patient before the doctor did and was responsible for some receptionist duties. In fact, when the receptionist was on holiday I did all the reception work and the nursing work. I also used to home visit on occasion. At this time, nursing leadership structures and training was only available in the local hospital in a nearby city.

Looking back the provision of service was at the level of primary medical care and maternity care. The nursing work was generalist in nature and involved activities such as venipuncture, wound care, triage and antenatal care and carrying out GP delegated procedures or assisting the GP. The practice was very busy and consequently considerable energy was devoted to getting through the large numbers of people wanting to see the doctor each day. If the GP was called on to deliver a baby then the receptionist and I managed the practice. The practice population was located in the town, rurally and close to a large rural industrial site. Due to the distance from a hospital emergency department, we also responded to a number of accidents.

As a young mother, I worked part-time in a private hospital and then in the 1990s I was back in the community working as a district nurse and later as a community ear nurse, a role that involved working in a mobile 'ear clinic' enabling the early diagnosis and treatment of glue ear in children. Both these roles were in areas that were seriously affected by economic downturn and rurality and in many instances, poverty, unemployment and poor education contributed to high rates of disease and injury. At this time, the effect of changing government policy and priorities alongside increasing marginalisation of Māori propelled me into involvement with groups that sought to bring about social change. During this time, I felt frustrated by way in which the competitive contract environment constrained nursing practice. 
In 2001, I returned to nursing in a general practice that served a population affected by high levels of deprivation and reduced access to health care in the previous decade. At this time, the implementation of the PHCS began to change the approach to primary medical services. This was a challenge to both the structure and traditional model of general practice but at the same time became an opportunity to expand nursing practice. For example in the practice where I worked we became more involved in the management of chronic conditions, sexual health and hormonal contraception, immunisation, comprehensive wound management and cervical screening and were able to initiate several new nursing services to enable certain population needs to be met. This expansion in services reflected international trends in general practice contexts (Patterson, Del Mar, \& Najman, 1999; Walsh, Roe, \& Huntington, 2003).

In 2004, I wrote this practice story whilst trying to articulate the dimensions and nature of my practice:

On a recent busy Friday my day included: a check for sexually transmitted infections (STI) and contraception counselling for a young prostitute; assessing, referring and then nebulising a young girl with acute asthma then creating an asthma action plan for her and her family; assisting with a male catherisation; vaccinating a five month old baby; carrying out an ECG; suctioning ears for a child with bilateral suppurative otitis media; checking another child with sore ears and then referring her to the GP with a throat infection; carrying out an aural toilet on an adult and then talking at length with a patient who was newly diagnosed with type 2 diabetes about the impact of his diagnosis, dietary change and the use of his new glucometer, and then a consult with a woman with dysuria. In between this, I fielded patient phone calls that involved phone advice, triage, worked with the GP to do a number of repeat prescriptions, carried out several wound assessments and dressings, completed 2 patient referrals to District nurses, liaised with a rest home over the care for an elderly patient who was under care of the GP and liaised with pharmacy 4 times over medication queries. 
On paper this seems like an extraordinary day but it was relatively normal day in general practice that provided both acute and medical care.

Reflecting on the above, the dimensions of my practice included assessment, nursing diagnosis, intervention, planning and evaluation and included health education, screening and surveillance, triage, liaison with community health practitioners such as District Nurses, hospital, specialists, laboratories, other health centres, Plunket Nurses and kaiawhina, police, victim support, St Johns Ambulance, ACC, rest homes and other government agencies. Within the practice we are also responsible for sterilisation, cold chain monitoring, infectious disease notifications, ordering of equipment, resources, medication and upkeep and audit of all emergency equipment, patient recalls for follow up tests etc, practice protocols and standing orders.

I left general practice because I felt disillusioned with the way that the business model at times prevented the expansion of nursing services, particularly in response to the population need. I subsequently took up a new role as a nurse educator in and educational institution. Whilst working with practice nurses I discovered that many remained poorly paid, were fulfilling roles of receptionist and assistant and were unable to expand their skills or even take time off for clinical nurse education without a level of anxiety and stress when trying to negotiate leave. In addition, any support to develop and expand their clinical skill within the practice was not always readily forthcoming. Certainly, the opportunity to initiate new services was constrained by a number of factors and dependent on the goodwill of the employers or management.

Two comments in particular sparked my concern about the visibility and value of practice nursing:

Nurses are good at ticking boxes

Comment from a female GP

Within the practice, I am an income-generating unit

Comment from a female practice nurse 
While these are isolated anecdotal comments, they highlight the perceptions that nurses confront and the way that nursing identity and work can be positioned within general practice. These quotations imply that practice nurses do nothing more than perform prescribed checks and tick boxes to achieve pre-set goals. The inference is that nurses are good at task-orientated roles and therefore best suited to this functional way of being. Secondly, the remark suggests that nurses are a commodity rather than a resource to support population need. An alternative view would be to suggest that practice nurses are efficient and able to provide a systematic approach to patient care.

Currently I work in an organisation that provides management services to a general practice network and primary health organisations in the role of 'Nurse Liaison'. The position involves the provision of pastoral support for practice nurses, advice on clinical matters, organising and delivering education and working to facilitate nursing potential in general practice in line with the PHCS. A team of 'nurse liaisons' work with a Director of Nursing to realise this and a key philosophy is that nursing leadership is vital to facilitate and guide innovation and professional practice.

Part of a wider project within our organisation is to capture data from patient management systems to inform the conceptualisation of nursing work beyond traditional task and function and ultimately support workforce recruitment and retention and nursing professionalism. This is of particular importance, for as Besner (2004) has noted, the development of patient information systems is at risk of being simply built around medical paradigms. In the GP context, the fee-for-service structure is related specifically to medical consultation or specific procedures such as cervical smear, immunisation or administration of medication. Currently nurses in New Zealand can become 'health providers'. However as this is linked to medical classifications the accompanying health education, health promotion or inquiry into lived experience of the patient may not considered a recognised classification under present patient management systems. In addition the billing still occurs via the GP and therefore "it is very 
difficult to measure this income (and therefore audit) practice nursing services at a PHO level" (Minto, 2004, p. 11).

\section{The invisibility of practice nursing}

A number of New Zealand nurses and nurse educators (Jamieson, 2002; McKinlay, 2006; Minto, 2006) have reiterated that the potential for practice nursing is constrained by traditional models and a failure of the government to make funding for nursing work visible or valued within the general practice context. Minto additionally believes that shared governance models such as those of magnet hospitals would make a difference to the nature of practice nursing but states that due to long-term employment relationships, "it is difficult for many GPs and practice nurses to separate the employee/ employer status from the professional status" (p. 170). Therefore, traditional issues of power and autonomous practice continue to create tensions and indecisiveness when developing nursing potential in daily work.

Nursing voice and visibility is fragmented both inside and outside the practice and the nature and complexity of practice nurses' day-to-day work is unclear. As stated previously, at present nursing work in general practice is only measurable in terms of screening data, fee-for-service data or in the context of medical work. Moreover traditional gender, medical and managerial constructs and discourses affect nursing professionalism and development and nursing difference remains constructed by a medical environment (Goodman, 2000; May \& Flemming, 1997; Roberts, 2000). As Dew and Kirkman (2000, p. 131) state:

The gender division of labour within medicine can be seen as a logical extension of the male-female role-relations in society where women are expected to possess the expressive, emotional, and caring qualities while men are expected to be instrumental, active and authoritative.

Practice nurse work needs to be clearly articulated and more visible rather than continue to be in the background and subject to political and business rhetoric. As Minto (2004) again asserts, 
Practice nurses are invisible in the funding and billing formulas. The charges are billed to and from the PHO through the GP as the provider of end service users. This makes practice nursing services invisible... as outcomes of expanded nursing services...are not fiscally visible (p. 11) .

The invisibility of nursing is not a new phenomenon and it has always been difficult to measure nursing work that is often intangible (Buresh \& Gordon, 2006; Pearson, 2003; Roberts, 2000). Often this work is unseen and unrecognised because it involves caring and relational processes rather than specific cure or treatment. As Jonsdottir, Litchfield and Pharris (2004) state, the relational core of nursing has gone astray amongst the current emphasis on technology and outcomes. Therefore relational nursing as a partnership where "the nurse is fully present to the patient and relates to the patient with open attentiveness" to "collaboratively seek[ing] meaning in their complex and often chaotic health circumstances" (p. 243) is lost. Furthermore as Lawler (1997) notes nursing is nowadays constrained by economic considerations and value is only measured in terms of "productivity, cost effectiveness and efficiency" (p. 41). This premise is reiterated by Hardy, Garbett, Titchen \& Manley (2002) who conclude that the caring discourses of nursing are in conflict with management philosophies. Additionally the reflective nature of nursing is unseen in the practical or visible aspects of the role.

I believe that practice nurses must take the opportunity to talk about the breadth of their work and capability in positive ways, and position themselves alongside and in support of the new models of nursing that are emerging within general practice. Likewise, it is important that those who work alongside practice nurses are able to understand what nurses do. Furthermore, nurses need to claim and construct the nursing reality in this context, rather than let it be done by others (Buresh \& Gordon, 2000; Clark, 1997). As Spilsbury and Meyer (2001) state "nursing needs to make bold statements about what it has to offer" (p. 6). 
May and Flemming (1997) suggest that, "the value of narratives - of professional depictions of self at whatever level - is that these act as cultural resources to convey the virtues of professional acts" (p. 1099). Therefore this study aims to add to this knowledge by providing an experiential view to inform policy makers and PHC leaders. As Hughes (2006, p. 95) notes in her discussion of innovation "the best innovators systematically use old ideas as raw material for one new idea after another in a 'knowledge brokering cycle'. Therefore in order to continue to be innovative nursing needs to consider existing premises and capabilities.

This chapter has discussed the current status of practice nursing in New Zealand and explored views of nursing invisibility in relation to medical and economic paradigms and discourses. The following chapter examines research that has informed the view of practice nursing in New Zealand and overseas and identifies a significant gap in New Zealand nurse led research. 


\section{Chapter Three: Literature review}

The significant diversity of practice nurse work makes it difficult to articulate a precise role from other community based nursing services (Halcomb, Davidson, Daly, Yallop \& Tofler, 2004, p. 137).

Interestingly as the practice nurse role has expanded and developed over the last ten years in the United Kingdom and Australia, nursing research has developed alongside. In New Zealand, despite similar developments, research of the practice nurse role has not occurred in any great depth. There has instead been more emphasis on the development of new models of care and the relationship of the practice nurse role to specific disease states or population groups. There is no study similar to the one designed in this project either nationally or internationally.

In part, the invisibility and voice of practice nursing can be related to this scarcity of research. Whilst publications like the Practice Nurse Journal, published quarterly by the College of Practice Nurses in New Zealand, provides ongoing commentary related to practice development with news articles alongside clinical advice and education, as with most professional journals the publication remains within the practice nursing community. Therefore, the public and other health professionals have no clear picture of nursing work or knowledge in general practice outside their own experiences. As the authors of the Investing in Health: Whakatohutia te Oranga Tangata document (Expert Advisory Group, 2003) noted fragmentation of PHC nursing roles creates isolation and prevents effective provision of service within communities.

The College of Nurses Aotearoa (2001) in their position paper on PHC nursing believe that a number of critical thoughts need to be contemplated in order to develop PHC nursing to its full potential - two of these being: 
How can changes be implemented so as not to create a threat or division amongst other health service providers in the PHC sector?" and,

What mechanisms will best ensure primary health care nurses and medical practitioners work in a way that complements the distinct contribution that nursing and medicine make in the sector?

The development of nursing services without informative knowledge of current experience adds to continued fragmentation and uncertainty therefore undermining the effectiveness of changing models of nursing care such as nurse-led clinics and practice nursing roles that include home visiting and case management.

\section{The search process}

A search of the Combined Index of Nursing and Allied Health Literature (CINAHL), ProQuest, and Medline databases was conducted using the search terms 'practice nurs*' and combinations of key words such as 'nurs* and general practice' or 'nurs* and primary health care', 'nurs* and community and New Zealand'. The search was limited to a period of years from 1999 to 2007 as this aligned most closely with the PHC initiatives. An exception to this was the use of the one New Zealand publication that provides an overview and picture of practice nurse work in the 1990s, albeit aligned to clinical task.

The majority of journal articles found were in relation to specific disease states, inter-professional team function, innovation and development of primary health care clinics or disciplinary debate rather than of the actual role itself. To widen the search I conducted a hand search of New Zealand nursing journals and an online search of specific nursing and general practice journals. Reference trails followed from retrieved articles then led to further literature.

\section{New Zealand perspectives}

As stated previously practice nurses in New Zealand currently work alongside general practitioners who serve a particular population and community defined 
by location and formal practice enrolment. Prior to 2001, some practice nurses were already working in roles developed in response to population need and supported of general practitioners in rural or underserved areas in a variety of ways.

New Zealand studies of relevance to this research relate to the work of practice nurses with people with diabetes, consider practice nurses working in rural areas, practice nurses delivering specific interventions and one unpublished work that explores nursing discourses in general practice. These studies are considered below. Only one study conducted in the Waikato found that the nurses' patterns of care usually involved follow up work or consulting with patients who presented with undefined symptoms (Davis et al., 1999). Interestingly in this study practice nurses believed that they established good rapport with their patients and were not likely to charge a fee. While relevant, these study data are quite old (from 1991-92) and were collected as part of a larger survey of GP practice patterns. The study did however highlight the need for further research to define the current and future role of the practice nurse.

Kenealy et al. (2004) explored the character of New Zealand practice nurse work in relation to people with diabetes and the increasing level of diabetes management undertaken by general practice teams. This longitudinal survey carried out in conjunction with a wider diabetes research project surveyed practice nurses in one geographical area on two occasions over a period of nine years. Project findings showed that generally the nurses were staying longer in one workplace and had undergone postgraduate education related to diabetes management over the duration of the study. In addition they were engaged in complex diabetes management, changed their practice to involve family members and had more involvement in screening, education, and support patient management of aspects of their diabetes such as injection technique, glucose self-monitoring and foot care. Findings showed that the practice nurse's role was still "typically moulded around that of the GP, and the patients who attend the GP on a given day" (Kenealy et al., p. 69) and 
that nurses were under-utilised Furthermore, further research to explore the potential of the role was needed.

In 1999, Jean Ross surveyed 41 rural practice nurses and concluded that there was a need for education to support advancing nursing practice in rural settings. Ross found that rural nurses were often involved in community projects that "would normally be considered outside the role of the nurse within the formal healthcare service" (Ross, 1999, p. 254). The challenge of articulating the exact nature of their expanding role was highlighted, alongside concerns about preparation and support. Many of the nurses surveyed were providing expanded nursing care with little educational support, were often working in isolation, both geographically and through lack of professional support.

Two additional studies in New Zealand illustrate role development and consider PHC nursing discourses. Pullen, Cornford, McLeod, de Silva and Simpson (2005) evaluated a smoking cessation initiative in general practice. They found that practice nurses were often constrained by time, cost and other roles in the practice such as reception duties when initiating smoking cessation programmes. In addition, lack of nursing autonomy and overall practice commitment constrained the potential of health promotion. On an alternative note Clissold (2006), considers that nursing discourses which foster the notion of the PHC nurse have not been realised by practice nurses therefore somewhat negating the ethos of PHC.

\section{Changing practice models}

There is little doubt that nurses are expanding and advancing practice in line with the principles of the PHC and engaging in new models of care to meet population need both nationally and internationally. The emergence of nurse practitioners and advanced practice nurses working in PHC contexts in the United Kingdom (Sibbald, Laurent \& Reeves, 2003); New Zealand nurses working in nurse-led clinics in schools (Clendon \& White, 2001), and, nurseled clinics developed in response to GP shortages have highlighted the 
changing nature of nursing and the issues that accompany this. For example Rosen and Mountford (2002) found in their study of nurse-led walk-in centres in the United Kingdom that nurses dealing with a varied case mix requiring a range of assessment, diagnosis, referral skills and knowledge, and role definition a complicated proposition. They noted that:

Given the varied case mix seen by walk-in centre nurse, many tried to describe how their role fitted between 'traditional' nursing and general practice. Several emphasised that they were not 'mini general practitioners'... when pressed on why this distinction evolved, nurses emphasised the importance of communicating with patients, giving them space to tell their stories and not rushing them, and providing opportunistic advice and health promotion (p. 241). In addition Walsh, Roe, and Huntington (2003) stated that "the difference between GPs and nurses working in primary health care is that GPs are holistic in terms of the overall medical status of patients whereas nurses are holistic in terms of dealing with patients emotional and social needs" (p. 338).

\section{The possibilities of the practice nurse role}

In general, international research literature reveals that practice nurses are well positioned to provide effective case management and can have an impact on a range of disease states (Caldow et al., 2003; Eve, Hodgkin, Quinney \& Waller, 2001; Shum et al., 2000). Such roles may involve taking on minor illness work to free up GPs or managing chronic care in collaboration. In particular the research of Pritchard and Kendrick (2001), although carried out in only one general practice in the United Kingdom, highlighted the ability of practice nurses and health visitors to successfully manage acute minor illness in general practice after specialised education.

However, recurring concerns that included uncertainty in relation to developing roles and role boundaries (Williams \& Sibbald, 2003), difficulties providing continuity of care with part time staff, lack of strategic leadership, tension surrounding traditional professional boundaries and lack of time or complex working environments affect this potential. For example Ross, Rink 
and Furne (2000) discovered there was a "lack of common values about integrated nursing teams" (p. 265), when evaluating the concept of selfmanaged integrated nursing teams ${ }^{2}$ in primary care. There is no doubt that a lack of formal leadership structures has contributed to these variations (Patterson, Del Mar \& Najman, 1999; Walsh et al., 2003) alongside disparate policy development (Stark, Warne \& Street, 2002). In some instances improved models of care were inhibited by historical nursing divisions and work patterns (Goodman, 2000).

One extensive literature review found that the potential for nursing practice in general practice was significant. However, existing roles were diverse and barriers to expanding roles included the ad hoc nature of development and variability in the work of practitioners. Halcomb, Davidson, Daly, Yallop and Tofler (2004), noted that:

Practice nurses have generally developed their own individual roles based on local needs, individual practice demands, their perceived skill level and personal confidence. The significant diversity of the work of practice nurses makes it extremely difficult to articulate a precise role description, or differentiate their role from other community based nursing services (p. 137).

Again, role uncertainty prevails and professional identity is unclear. Interestingly the Centre of Innovation in Primary Care study in the UK speculated that "practice nurses are in some sense like a "lost tribe...they lack both standing and profile within the profession of nursing” (Eve, et al., 2001 p.21).

\section{Expanding and advancing practice}

In the United Kingdom, the PHC movement has taken a number of forms including the setting up of PHC trusts and the development of a range of nurse led services to counter the effect of diminishing numbers of general

\footnotetext{
${ }^{2}$ Integrated nursing teams in the UK consist of primary health care nurses - practice nurses district nurses and health visitors work together, manage and organise care to a particular population - they are usually aligned to a general practice.
} 
practitioners. Nurses tend to work in collaboration or as substitutes for general practitioners in the management of chronic disease and minor illness (Sibbald, Laurent \& Reeves, 2006). The case for nurse substitution of GPs is viewed as a valid strategy to support communities in addressing in some of the inequalities and improving access to primary health care and this move has been viewed positively by patients (Sibbald, 2003).

The development of nurse-led clinics and expanding primary health care nursing roles has been widely investigated internationally. However, again ambiguity of roles, variable levels of education (Pascoe et al., 2007), structural barriers, inconsistent physician collaboration and shared care (Willis, Condon \& Litt, 2000) along with low remuneration are notable concerns (Todd, Howlett, MacKay, \& Lawson, 2007, p. 25). Notably Faithfull and Hunt (2005) discovered that "developing advanced roles requires enhanced credibility for the advanced practitioner as well as a change in organisational culture in order to be successful. Valuing nursing as a therapy in itself is often overlooked" (p.449).

Within Personal Medical Service (PMS) pilot sites in the United Kingdom nursing roles were extended to include ordering of diagnostic tests or establishing nurse triage services to address GP shortages and a lack of PHC services available to vulnerable populations (Lewis, 2001 ). From 1998, these pilot sites were specifically established to increase nursing services and expand nursing leadership in PHC contexts. At this point 'nurse-led' was positioned as a "culture of nursing equality and patient focussed services" (Lewis, p. 10). In some instances nurse practitioners were employed to work as first point of contact providers of medical care and in other pilot sites practice nurses focussed on community needs and addressed these by working collaboratively with GPs and other team members such as home visiting nurses (Walsh, Roe \& Huntington, 2003). Traditional structures that previously inhibited extended roles were broken down leading to nurse referral to secondary services, nurses seeing patients from the point of diagnosis through to the planning and evaluation of care, increased interdisciplinary 
vision and an improved understanding of professional differences between GPs and nurses.

For Evans, Drennan and Roberts (2005) the barriers to improving care for older people in general practice were lack of time, the emphasis on meeting monetary targets for immunisation and cervical screening. Those nurses who had postgraduate education were better equipped to provide a case management role however variation between nurses and practices was significant. It seems that although changing practice increases continuity of care and provides improved accessibility there is concern that if nurses are to take on expanded or extended roles then education must be able to support this trend (Harrison, Dowswell, \& Wright, 2002; Sibbald et al., 2003; Walsh et al., 2003). As Sibbald et al., state, "the pace of service development in England in the 1990s often outstripped the ability of training programs to equip nurses for their new roles" (p. 1). In addition, concerns included uncertainty in relation to cost effectiveness, loss of continuity of care and the possible duplication of existing services.

In Australia there is increasing impetus to expand the role of the practice nurse in health promotion and prevention of illness (Price, 2007) and particularly in response to increasing numbers of people with chronic and complex health conditions. Similar to the UK experience, practice nurses are required to provide support for the diminishing GP workforce (Pascoe et al., 2007). An increase in practice nurses in Australia has only occurred due to government funding to rural general practice in 2001 and then to urban practices in 2005. In this instance, Australia is well behind the UK and NZ (Halcomb et al., 2004) and nurses have encountered levels of resistance and uncertainty about the role from the medial profession (Gibson \& Heartfield, 2005; Smith, 2006 ; Stevenson, 2006). Interestingly as Patterson, Muenchberger and Kendall (2007) stated,

Before 2001, only about $40 \%$ of general practices in Australia employed a nurse. These nurses focused on immunisation, wound care, sterilisation, assisting with procedures and tests, some practice 
management roles and receptionist duties. The nursing aspect of their role was largely hidden, unrecognised, obscured and undervalued in terms of government resource allocation (p. 232). Therefore although defined as an "emerging specialty" (Halcomb, Patterson, \& Davidson, 2006, p. 376) with huge potential in the general practice team, the role has lacked practice nurse leadership, cohesive professional development and research. These authors reviewed 35 years of Australian literature and discovered that the role of practice nurse was both complementary and collaborative but "broad and diverse" (p. 378).

Notably the availability and flexibility of practice nurses were key factors in patient satisfaction and often led to opportunistic intervention and education (Phillips et al., 2007). Therefore, despite limited nurse time working in nurseled consultations value is perceived in the ability of the nurse to make time for patient concerns, gain insight into the lived experience of the individual and family and often "reveal valuable clinical information" (Phillips et al., 2007, p.140). Earlier Australian research found that practice nurses consistently provided opportunist education and support based on conversation with patients whilst carrying out delegated medical care. Lack of funding was directly related to lack of autonomy or ability to define the scope of practice, profile and minimal expansion of the role (Gibson \& Heartfield, 2005;

Patterson, Del Mar \& Najman; 2003; Price, 2007). In addition, the multiplicity of work practices prevented clear articulation of roles or differentiation from other community nursing roles contributing to uncertainty (Halcomb et al, 2004). Of note is that practice nurses still believed themselves to be in the role of assistant to the GP (Patterson, Del Mar \& Najman).

Overall, the tasks and activities that practice nurses undertake are extensive and ranges from home visiting to receptionist duties. Clinical responsibility includes child health, chronic care, minor illness and acute care assessment, wound assessment and treatment, referral management, health education, managing recalls. Patients value extra time given and the listening capacity of the nurse (Branson, Badger \& Dobbs, 2003). Although nurses may not see the 
same number of patients as GPs, they spend time between appointments undertaking follow up work thereby providing efficient support for GP work (Eve et al., 2000; Kenealy et al., 2004; Phillips et al., 2007). Like their medical colleagues they developed their role around the population and practice, therefore roles and activities varied considerably and a "broader range of skills than nursing in hospitals" was required (Gibson \& Heartfield, 2005, p. 55).

Descriptive and survey research provide one view of practice nursing but as identified by Halcomb et al. (2004), "little is known or published about [practice nurse]) work... about the typical background and experience of the practice nurse, the variations of their role between individual practices and their contribution to chronic disease management in general practice" ( $\mathrm{p}$. 136). Workload issues, insufficient education and lack of protected time along with isolation and lack of a team approach meant that nurses felt ill prepared and unsupported when working in changing general practice environments and expanding practice (Breen, Carr, Mann \& Crossen-White, 2004; Gibson \& Heartfield; 2005 Greaves et al., 2003). Whilst introducing new nursing roles into general practice it is vital to additionally provide a clear picture of practice nurse work so that resistance and role confusion is diminished. Hegney et al. (2006) noted that although consumers felt at ease with practice nurses, they were less sure about advanced roles and nursing qualifications. Overall, there is a sense of uncertainty in relation to advanced and expanded practice. In addition, a nurse led voice in research is missing in the drive to find cost effective and fast solutions to increasing health crises.

This literature review illustrates that there is considerable ambiguity in relation to the nature of roles and the context of changing models of primary health care. Nurses, GPs and patients are additionally unable to clearly articulate the particular dimensions of nursing in general practice. To address this gap this study sets out to illuminate the day-to-day experience of a group of practice nurses in the New Zealand setting. The next chapter presents the research design, methodology and method through which this study was conducted. 


\section{Chapter Four: Methodology, Method and Design}

Narrative can help in developing nursing knowledge by its emphasis on practice around what nurses are already doing rather than by analysing practice from a particular theoretical or methodological perspective. In our view, research using narrative is more respectful of nursing practice since it does not seek to impose a pre-existing methodological framework upon it, and it takes seriously the stories that practitioners tell about what they do (Carson \& Fairburn, 2002, p. 17).

Three sections make up the following chapter. Firstly, an exploration of narrative methodology occurs. This is followed by an overview of the research design and method used to for the data collection. The final section of the chapter outlines and describes the processes of interpretation and analysis. I have chosen to use a narrative inquiry approach in order to make visible the experience and meaning of practice nurses' day-to-day practice. This research methodology fits favourably with the intent of this project because there is value given to the perspective of the participant and to an extent the experience of the researcher and the potential audience.

\section{Methodology}

To reiterate previous chapters, my underlying assumption is that nursing practice remains invisible and often undervalued. In addition, as Buresh and Gordon (2000) state, "one of the best reasons for explaining nursing to others is that it helps nurses to appreciate their work" (p. 22). Nursing as a profession also has a responsibility to the public to provide understanding of nursing particularly when this relates to the care of families and the structure of health systems. Therefore the premise of experience and retelling to make meaning can be seen as the "reconstruction of life's dailiness and seeing connections that were previously unknown suggests anew what an experience might mean" (Lindsay, 2006, p. 31). 
Narrative inquiry is a research method that gives prominence to stories and the significance that the telling and reconstruction of sequences of events has on making meaning and sharing understanding with others. It is a method where people and their experiences are central (Carson \& Fairburn, 2002). As a method of research, narrative inquiry is relatively new, is still developing and in many ways complex (Chase, 2005; Mello, 2007; Wood \& Giddings, 2003). However, story telling is both an ancient and current way of social and cultural depiction and communication (Stake, 2003). As Burns and Grove (2005) state, "a story can be a powerful way to make a point" (p. 555) and the development of narrative is a way of presenting data "designed to convince through its lifelikeness" (Liamputtong \& Ezzy, 2005, p. 125).

\section{Theoretical standpoint}

The underlying assumption of narrative inquiry is that as human beings, we traditionally tell stories and in the process of telling stories, we are able to give meaning and interpretation to events and lives (Koch, 1998; Polkinghorne, 1988; Sandelowski, 1994). It is also a way to share our understandings with others who hear or read stories, remembering that in the process of reading or hearing a story, interpretation, from the reader's perspective, starts all over again. Implicit in this process is the organisational nature of the story. This enables meaning to be conveyed which can be validated by a particular audience (Elliot, 2005; Liamputtong \& Ezzy, 2005). Whilst providing a mechanism to transport and impart cultural values (Polkinghorne), most important is that fact that narrative gives the perspective of those telling the story.

Narrative inquiry is situated on the continuum of qualitative research within the interpretive paradigm (Crotty, 1998; Wood \& Giddings, 2003). As opposed to a positivist approach that seeks to present findings as an objective view of the natural world (Hughes \& Sharrock, 1997), the interpretive approach unashamedly seeks to represent and understand knowledge and experience from the point of view of all those engaging in the inquiry researcher, participant and audience. This research therefore takes a 
constructivist approach to knowledge generation as the inquiry involves making sense and giving meaning and respect to the individual experience within the social context (Crotty, 1998). As the philosopher Weber, cited by Hughes and Sharrock (1997) propounds:

Interpretative understanding gives social observers a method of investigating social phenomena in a way that does not distort the social world of those being studied. Since the essence of social interaction lies in the meanings agents give to their actions and environments, all valid social analysis must refer back to these ( $p$. 101).

The process of research is therefore displayed through writing that shows "how the horizons of the interpreter and interpreted are fused" (Koch, 1996, p. 177). Therefore, central to this methodology are an understanding of the importance of language and the processes of understanding self. Consequently engaging in interpretative research involves a commitment to express understanding of "what is real for you and what is important in your life" (Koch, 1999, p. 22). In effect, this is the ontological position.

Building on from this positioning, each interpretation should be contextual and the process of validation and reliability occurs alongside the ethical stance of the researcher throughout. Williams (2003) believes that there must be an amalgamation of understanding, reflexivity and interpretation and that the degree to which this develops is dependant upon how much the researcher knows about the context, setting and those involved. The position of the researcher is one that cannot be detached from what is going on and is subjective rather than observing or identifying the objective 'facts'. The researcher, whilst creating the research text, engages in a process of reflexivity to maintain levels of rigour (Koch \& Harrington, 1998) and considers carefully how to "preserve, and respect their content and meaning" (Mello, 2007, p.233). In addition this approach considers possibilities of social change or social action (Burns \& Grove, 2005) that may occur, for example 
previously silenced voices are enabled to "challenge an audience's assumptions or actions" (Chase, 2005, p. 668).

Historically, narrative inquiry has developed from a range of fields including anthropology, psychology, sociology, education and health (Chase, 2005; Elliot, 2005) and within some of these fields case studies are the basis for narrative work (Stake, 2003). In anthropology, the process of narrative has developed out of ethnographic inquiry where the researcher has explored culture as a participant observer and has collected life stories or biographies. In psychology, narrative is utilised to inquire into the psychosocial aspects of people's lives through analysis (Chase, 2005). In sociology, health and nursing, narrative inquiry provides a way to understand experience and portray this to others (Bowers \& Moore, 1997; Sandelowski, 1994) and in education, narrative research experience often links to the process of learning, education and professional knowledge (Clandinin \& Connelly, 2000; Lindsay, 2006; Lindsay \& Smith, 2003).

Just as there are different forms of research methodology, there are a number of narrative forms and structures. These are of significance because they provide a basis for the development of new ways to analyse and write the research project. One of the most interesting narrative forms is that of 'testimonio'. This form of story telling arose from Latin America and became significant in response to oppressive regimes that sought to marginalise and subjugate Latin American peoples. The testimonio became a way for communicating to the world the plight of these peoples. Often these narratives were a powerful recounting of suffering and death that did in fact mobilise global protest. In this instance the position of the researcher is one of a "supportive voice" (Chase, 2005, p. 665).

Some debate surrounds testimonio in relation to 'truth'. However despite this many of these narratives have provided a voice for marginalised and silenced peoples (Beverly, 2005). Therefore, Chase (2005) particularly asks narrative researchers to question the purpose and form of narrative in relation to social 
action and in relation to challenging the metanarratives or overarching commonly held stories that audiences hold onto. In some instances, the turning of a narrative into a performance is one way of achieving this. As Guba and Lincoln (2003) note, the position of the inquirer is "passionate participant and facilitator of multi-voice reconstruction" (p. 196), as opposed to an inquirer who maintains separation from the subject.

In spite of this premise, the interviewer must still take care during the process of data gathering to consider the participants' meaning. In addition, the position of the audience is significant as they can confirm or collaborate with the final product and therefore may influence how the research report is structured. The use of narrative, as opposed to survey or semi-structured or structured interview questions, means that the narrator is in effect enabling participants the freedom to chose events and stories and develop their own constructions. During the process of listening to stories, attention to the process of in-depth interviewing occurs and care needs to taken that the interviewer does not direct or try to limit narratives or interrupt (Elliot, 2005).

To locate this methodology within nursing as a practice profession, Lindsay (2006) contrasts the use of a narrative approach and phenomenology in nursing research and states that "narrative inquiry contributes to nursing research as way to reflect on and reconstruct experience that shows how our actions connect to our identity and knowledge" (p. 42.). Similarly, Smith and Liehr, (2005) believe that narrative is a methodology that nurses can make use of as close daily relationships with patients provides opportunity to pay attention to patient's stories. McQueen and Zimmerman (2006) deliberately chose an interpretative narrative approach "because the goal of narrative research is interpretation rather than fact finding" (p. 476). Therefore, meaning and relevance of the individual experience are at the forefront of narrative in contrast to statements of fact or 'truth'.

In summary the significant facets of narrative inquiry are: 
- An acknowledgement and appreciation in the lived experience of people and the "temporal nature of that experience" (Elliot, 2005, p. 6) or in other words an interest in how stories are structured as a sequence of events with meaning

- A wish to involve participants as interpreters and contributors to knowledge generation

- A consideration of development and transformation over time (Elliot)

- An acknowledgment and awareness of self in the research and different positions as researcher, narrator and other identities

\section{Ethical considerations}

Ethics approval was obtained from the Victoria University Standing Committee of the Human Ethics Committee (see Appendix One) after submission of an application in accordance with the Ethics Committee process. Approval was granted on 13 August 2007 and in place for data collection to February 2008. Because I work within a specific PHO area, a key consideration of the ethics process was to locate participants outside this area to prevent compromising relationships with nurses that I worked with. I was additionally conscious that it was important to ensure that if participants felt compromised or destabilised during the interview, I would facilitate support for them via a local nurse leader. While this proved unnecessary for these interviews, it was important that this provision was available and is supported by the ethical principle of "goodness", which involves "safeguarding participants' rights, interests, and sensitivities" (Barton, 2004, p.523). In addition, this stance aligns with the articles of Te Tiriti o Waitangi that inform any research that involves Maori participants by considering tinorangatiratanga (self-determination and sovereignty); consultation and protection through the kawanatanga principle and participation through the principle of citizenship. Moreover, this research seeks to avoid creating generalisations or create stereotypes using reflexive processes and participant checks. 
One group of researchers who have used narrative to their advantage are feminist writers. Consequently research approaches have developed broader and more critical notions of reflexivity (Chase, 2005), in relation to the process of interviewing and recording of results in a way that does not further marginalise or create 'otherness' of women. For example, an acknowledgment of the "value-ladenness of inquiry" (Lather, 1991, p. 2) declares that researchers recognise and articulate their personal values, beliefs and perspectives clearly in the research so that this is implicit throughout, and issues of researcher participation and the role of participants is visible. For Koch $(1998 ; 2006)$ the use of personal journals in her research enables reflexivity and reflection whilst collecting stories, during interpretation and additionally provides a sense of rigour. In essence, "reflexivity is the critical gaze turned toward the self in the making of the story" (Koch p. 1184).

As an alternative to reflexivity, Clandinin and Connelly use the term 'wakefulness'. This term describes the practice of reflection and reflexivity that takes account of the subject position taken by the researcher whilst valuing the narrative and the experience that is articulated. The language of wakefulness is explained as responsiveness to stories and a critical analysis of self as a narrative inquirer and develops as thinking within a 'three dimensional inquiry space' (Clandinin \& Connelly, 2000; Clandinin \& Huber, 2002). The metaphor of the "three dimensional inquiry space" is employed to explain the process of "exploring life backwards and forwards in time, personally and socially and as located in place" (Lindsay \& Smith, 2003, p. 121) or giving significance to experience expressed through storytelling (Barton, 2004).

The process of reflexivity was continuous throughout the research process. I considered how I was presenting myself to potential participants and was concerned that I would be perceived as an 'expert' or 'academic' nurse. This critique of my positioning has influenced the processes of ethics application, the interviewing and the wording and presentation of the information sharing process both verbal and written. Throughout, I examined my own perceptions, 
assumptions and reality and considered how this would influence the data collection, narrative construction and findings. This thinking was recorded in my journal and illustrates my thinking and the development of ideas particularly after each interview and whilst listening to the interview tapes. Importantly in narrative inquiry, the process of reflexivity does not end at the time of completion of this project but continues into further dissemination and thinking.

The ethical stance additionally included taking time before, during and after each interview to chat. This involved sharing a little personal information and often making connections before the interview commenced. This I believe was a crucial part of the interview process to establish comfort and additionally assisted when corresponding with participants by email post interview.

\section{Participants}

The process of participant selection was purposive, nominative and snowball (Gillis \& Jackson, 2002). In the first instance, I approached nurse leaders whom I already knew and asked if they could put me in contact with nurses who worked in low cost access centres, or pass on the information sheet so that anyone interested could contact me directly by phone or email. This entailed a phone call to the nurse leader, followed up by an email with the information sheet attached. From this process, I was able to arrange interviews with two practice nurses. Once these first two interviews were completed, I asked if the participants knew of anyone else who would be interested in participating. Using this method, I made four contacts. However, only one was able to follow though with an interview. At this point, I made direct contact with two other practice nurses outside my area that I knew of from other networks, both these nurses agreed to participate. The participants were all women who worked in practice nurse roles outside the PHO in which I currently work. All received a small book or petrol voucher as a token of thanks from me. 
I was unsure how many times I should contact a potential participant, as there were a number of emails and telephone conversations before interview arrangement could be finalised. Coordinating time and place was complex - in part because of my own work commitments but also because of the work, life and family commitments of the participants. Travel time was a consideration and arranging telephone time was problematical. This was in part due to the potential length of the interviews. I was conscious of not wanting to waste anyone's time and additionally did not feel that I could keep trying to engage with potential participants if they did not reply to several emails or phone messages. In the end, I made approximately nine contacts, however only five eventuated in interviews. I am not sure why this was; perhaps it is an indication of the time of year, coming up to Christmas. Regardless of this small number, five participants is an appropriate number for an interpretive study, characteristic of and appropriate to an interpretative narrative inquiry that selects participants who meet particular criteria (Chase, 2005; McQueen \& Zimmerman, 2006).

I deliberately chose to interview nurses who worked in low cost access centres. These centres receive higher capitation payments or extra funding due to the nature of the enrolled population who may be located rurally or in low socio-economic areas. I believed that the experience of nurses in this context aligned well with the directions of the PHC strategy. However, there was no actual basis for this and by making this criterion for selection, I inadvertently denigrated the status of nursing work in centres funded by different formulas. In addition, this restricted the numbers of potential participants within reasonable travelling distance. It was also a challenge to explain to one of my network contacts - 'just why did I think that nurses working in non low cost centres worked differently?' This was a clear instance of my subjectivity influencing the progression of the study.

\section{Confidentiality}

Maintenance of confidentiality was achieved by the use of initials for transcription and the storage of recordings. Pseudonyms were given to each 
constructed narrative and no actual names were recorded except on the consent forms, which were kept confidential to me. During the process of interpretation and narrative construction all reference to any place or individual context was removed from the stories to prevent any participant being identified. Digital audio recordings, consent forms and transcripts were stored in a password-protected computer and any hard copies kept in a locked filing cabinet.

Once participants had agreed to be interviewed, I forwarded a copy of the information sheet and consent form for them to consider before the actual interview. I then sent a confirming email or made a phone call just before the interview to ensure that they felt comfortable progressing. All the participants agreed to be involved. At the time of interview, the information sheet (see Appendix Two) was read again, time for questions given and the consent form (Appendix Three) signed.

\section{Transcription}

Before any transcription occurred the nominated person signed a confidentially agreement (an example of this form is attached as Appendix Four). Once the recordings had been transcribed verbatim, I then checked for any missing or mistaken words. During this process, I was able to align the text to my interview notes while listening to each recording. The transcribed text was sent to participants after confirmation that they felt comfortable to receive them by email. Emails to and from the participants and myself were kept in a password-protected computer file.

Issues of time and care needed to access and review the data are not new concerns (Seibold, 2000). I listened to the tape as soon as possible after the interview (within the hour) and made initial notes and comments. Once the transcripts arrived, I was able to review these within 24 hours. It was tempting after the first two interviews to give weight to the commonalities and therefore make this the emphasis of the next interview. However, having agreed on my prompts within the ethics approval and with my supervisor I stayed with the 
plan. This I believe, given the small nature of this project, was an important strategy. The structure of the stories is based on the configuration of the interviews and this strategy is used to give the final product consistency.

\section{Interview process and reflection}

I initially conducted a pilot interview to test the unstructured questioning structure and flow. This brought up a number of issues that enabled me to refine the questioning process after discussion with my supervisor. For example, I was clear that I wished to collect stories; however, this was somewhat difficult because I was keen to hear the day-to-day experience.

The process of interviewing took the form of unstructured questioning or rather a framework that followed a series of prompts and probes (a sample interview schedule is included in Appendix Five). As a starting point, I asked participants to 'look back' to the time when they began practice nursing; I then used prompts to move the conversation to day-to-day experience. At different times in the interview, I encouraged more description or explanation. For example, "so it's a different kind of approach..." (Amy transcript) or "tell me a little more about that change ..." (Beth transcript).

To conduct the interviews I travelled to the homes of two participants, to one workplace, met one participant in a café and conducted one interview over the phone. I used a digital recorder, took notes throughout, and asked the permission of each participant if I could take notes whilst recording. Meeting two participants in their homes I believe enabled them to feel comfortable and although there were a few interruptions generally this process worked well. One interview was conducted in a workplace that was additionally a comfortable place to talk - quiet with minimal interruption. Despite the noise and foot traffic, the interview in the café went well; however, the background noise on the recording made it difficult to hear afterwards. In this instance, I was glad that I was able to listen immediately after the interview and that I had taken notes, otherwise some of the meanings and words would have been lost. 
The phone line and the digital recorder influenced the one telephone interview I conducted as I could hardly hear once the recording process had started. Additionally having no visual pointers, (such as body language cues) meant that I hardly interrupted at all, therefore the participant talked at length after initial clarification from me. Thankfully the recording was noise free so very easy to transcribe and listen to afterwards. Shuy (2003) notes that although there is a shift to telephone interviewing most research on this type of interview has centred on the responses of the interviewer rather than the respondents' perspective. Certainly in terms of reduced cost and travelling time, the telephone interview I conducted was effective and there was a linear approach to the interview as I followed the planned prompts. Shuy believes that one advantage of telephone interviewing is that there is less interference by the interviewer and this was certainly the case in my one experience.

Whilst it is problematic to draw any conclusions from one telephone interview, it is possible that if I had conducted more telephone interviews, I would have been able to involve a greater number of participants.

Overall, the process of interviewing proved to be more challenging than I expected. As a novice researcher, I found that I was starting to interpret and analyse during the interview instead of listening and following prompts or leads. The first interview felt quite disjointed and I consider I missed a number of opportunities to explore points further. This skill developed as I progressed with the data collection. In addition, as a novice researcher, there was a level of hesitancy, in part related to the uncertainty of the process of gathering data. This is illustrated in an example of a sample of my words at the beginning of one interview:

Right, umm, so [uncertain sigh], well, the idea is that I'll just... rather than a whole lot of structured questions I've got some sort of, leading questions and then we might veer off or you can veer off [embarrassed laugh] or whatever...

I found it difficult to remain quiet in the interview and when the conversation often went off on tangents opportunities to explore meaning were lost. The 
positive side of this is that it still provides a very natural story with pauses and breaks that typify story telling.

Whilst carrying out the interviews and during the interpretation and analysis process I discovered a number of roadblocks of my own making and I questioned my listening skills. Fontana and Frey (2003) point out that interviewing is more difficult that one expects and ambiguity exists within the spoken and written word. Clandinin and Connelly (2000) suggest that there are a number of complexities to be negotiated in fieldwork and that tension exists because of the relational nature of narrative work. This is clear for me in this research - I was conscious that I did not want to use too much of the participant's time even though none of them indicated that this was a problem. During the interview itself, I found there were tensions when there was silence, and when I wanted to add in my own experience about practice nursing - for example my values about the importance of opportunistic interventions or triaging and fitting people into the day. This aligns with the "insider position" that affects the research process and accounts for the tendency to take "common experiences for granted" (McEvoy, 2001, p. 49). This in turn can affect balance, and the questioning processes and responses.

Plummer (2001) advises that preparation and planning are vital to a successful interview. I would worry beforehand that something would go wrong especially when I had to travel some distance to find the meeting place. This was quite an anxious time - not just the anxiety of meeting someone new and having expectations about the encounter but also of getting lost or being late. Consequently, I would leave a lot of time in advance to make sure I was well on time. I also carried everything extra that I could think of - spare batteries, spare pens and paper, consent forms, information sheets and the instructions for the digital recorder - nothing worse than finding that you could not remember how to turn it on or find the right folder, or even worse record over the top of a previous interview. 


\section{Subjectivity and bias}

As with any research, issues of subjectivity require careful thought and monitoring. For this reason, explanations of my assumptions and positions occur in Chapter One and Two. During the interview and analysis processes subjectivity was a factor that I have taken care to make explicit through reflection by stating my beliefs clearly. The process of negotiation during the interview is complicated and relates to aspects of intersubjectivity. If one regards interviews as sites for the development of social construction and identity (Rapley, 2001) then this occurred with the language that I used to produce a specific identity - that of 'practice nurse'. For me this reinforced the importance of the pilot interview and testing responses in order to identify potential tensions or inadvertent positioning that could affect responses.

I am reassured by Wengraf (2001) who suggests, “one of the key arguments used to justify narrative research is that many of the assumptions and purposes, feelings and knowledges, that have organised or organise a person's or society's life are difficult to access directly" (p. 115). For that reason, the interview is not easy to predict or plan when using unstructured questions. As Holstein and Gubrium (2003) state, "meaning is not merely elicited by apt questioning, nor simply transported through respondent replies, it is actively and socially assembled during the interview encounter" (p.4) and when asking people to speak about their lives, interviews are a particular type of conversation.

As stated previously I chose to start my interviews with 'tell me how you came to be a practice nurse' as this enabled a temporal perspective - to think back about experience. The participants when looking back did not regret becoming a practice nurse and all identified themselves as 'Practice Nurses'. This is almost certainly due to the way I constructed the study, as on reflection I did not provide opportunity for them to identify as anything else.

I found that each interview was very different and each nurse had her own experience and context that influenced the way that she spoke about her work. 
In addition, during each interview, I reacted to the body language and linguistic nuances that often meant that a different tack was taken. While listening to the recording without the visual cues it was clear that I could have explored areas differently but had reacted to the visual feedback.

\section{Rigour}

Pellico and Chin (2007) make clear that the "aim of narrative is not certainty but believability" (p. 63), alongside considerations regarding clarity, articulacy and the capacity of the work to form the basis for further research. In other words, can others read, understand, and find connections with their own experience? In addition, rigour for this project is assisted by the use of the following strategies:

- $\quad$ Member checks of transcripts - this was completed by sending transcripts back to participants for comment and verification

- $\quad$ Maintaining the individuality of the narratives and therefore not making generalisations rather presenting these as connections

- An audit trail, visible throughout this thesis with evidence of the ethics approval, interview questions and findings presented as appendices

- Including reflective explanations (Koch \& Harrington, 1998). Plummer (2001) conceives of as reflexivity as a social consciousness and selfawareness, this links with the notion of wakefulness previously discussed. Instances of this occur throughout this writing.

Guba and Lincoln (2003) perceive reflexivity as the process of questioning biases and assumptions throughout the research. In many ways, it raises more questions and concerns that need exploration and for me this has highlighted my perceptions of practice nursing and context and how much this influences my emphasis - not only in this research but also in my current practice. During the interpretation, I kept a constant check back to transcripts and narratives to ensure that my 'voice' was not overtaking the participants 'voice'. In addition, the narratives have undergone revision a number of times to ensure clarity and the protection of identity. This aspect is of importance due to the relatively small number of practice nurses in New Zealand. 
I experienced uneasiness when constructing the individual stories that I would be able to represent their experience with authenticity and care. Finlay (2002) suggests that "as qualitative researchers engaged in contemporary practice, we accept that the researcher is a central figure who influences, if not actively constructs, the collection, selection and interpretation of data" (p. 212). I find this to be both a challenge and help. For this reason the narratives are constructions from the transcripts, a moment in time - temporal and contextual and personal, a representation and description of one person's experience and the meaning that surrounds it.

Holstein and Gubrium (1998) suggest that in order to appreciate stories and experience one takes care not to over-emphasise themes and make generalisations. However as Atkinson and Delmont (2005) suggest although individual narratives are perceived as personal there is in fact a sharing of cultural and social elements. For this work, there has been a fine balancing act and my position as interpreter is made clear by the analysis strategy used. This is a two-step process and I noted in my journal that each interview had a core spirit or overarching larger narrative that revealed both personal and professional subjectivities. To capture my interpretation of this I have used a quotation at the beginning of each narrative that I believe reflects these aspects.

\section{Interpretation and analysis}

To provide a robust analysis I have adapted two processes appropriate to the research question - 'what is the day-to-day experience of practice nurses in New Zealand?' In the first instance, I adapted the framework of Pellico and Chin (2007) to develop the story structure, a significant part of narrative inquiry. Throughout this process, I then applied three lenses of analysis adapted from Chase (2005).

In the first instance, Pellico and Chin's (2007) format incorporates the elements of 'plot' formation, and therefore reflects the nature of storytelling while keeping the storyteller at the forefront. It also highlights the significance 
and role of the audience. As this study is an illumination or clarification, the plot development and structure of the story is similar though all the narratives and is based on the original interview flow. Fundamental perceptions, strengths, revealed talents, and significant components in the experience are considered throughout this process.

The development of the narrative structure from text involves firstly the phase of attending at the commencement of the study that, involves thinking, exploring and writing about the context, current realities and knowledge. This extends to the listening process that occurs in the interview. This is followed by the phase of telling, enabling the participant's voice to be clearly heard through the interview process - in a longer study this process would involve conducting a further interview with the participants.

Once these steps are completed, then transcribing the data occurs. Pellico and Chin (2007) refer to this as the 're-listening' and reading followed by the process of constructing and reconstructing or 're-storying' of the stories. It includes returning the transcripts for comment and developing plot structure in keeping with the methodological principles. At this time, I made decisions about what to include and what to leave out in the process of story construction. This part of the interpretation involved developing a storyline from the text - finding the beginning, middle and end and choosing how to construct and place emphasis on particular elements. What is not included is a conversation analysis therefore no study has been made of linguistic phrasing. However, interpretation of the contextual, technical and nursing knowledge aspects is explained in the next process.

The next phase involves analysing the data - this process entails "creating distinctions among the stories and identifying similarities" (Pellico \& Chin, 2007, p. 60). During this process, I developed the connecting narrative and then contemplated the main connections that had emerged from the narratives. I consider that these narratives are representations of experience and meaning and believe that the narratives tell us a great deal about the day-to-day 
experience of practice nursing both collectively and individually. The process of annotation that accompanies the narratives illuminates the detail of the taken-for-granted day-to-day practice. As Gubrium and Holstein (1998) state storytelling provides an "endless supply of potentially reportable, storyable items, it is the incorporation of particular items into a coherent account that gives them meaning" (p. 166). In addition, the consideration of other texts and literature supports the recognition of patterning during the analysis (McQueen \& Zimmerman, 2006). This thinking forms the discussion chapter.

The final part of this framework is the reading or the time when the reader of the study or publication of the study becomes a site for interpretation. "The reading can be in the form of publications or presentations of the interpretation" (Pellico \& Chin, 2007, p. 60) but must show a clear structure of development for further interpretation as "plausible meanings of human experience" (p. 63). Utilising this framework ensures that the narrative structure is not bypassed by interpretation and therefore provides a view that appreciates the aesthetic view or the inherent diversity and individuality of the narratives as highlighted previously (Pellico and Chin). Essentially the process of story construction has created a compilation of stories that are connected but individual (Kelly \& Howie, 2007). Finally as part of the interpretation and analysis, it is important for the reader or audience to take account of the temporal and experiential nature of the narratives. As Mello (2002,) asserts, Our narratives contain unique individual worldviews, perceptions that are negotiated through the act of storytelling itself. The narratives we call data are illustrative, linguistically, of perceived human experience. As such their meaning is dependent upon context, time, place of telling, and audience response, coupled with the researchers' findings" (p 234).

Whilst using the framework explored above, I also applied three analytic lenses adapted from Chase (2005). Whilst Chase identifies these lenses as relevant for narrative research and clarifies them as divergent, she additionally states that, 
As researchers go about the business of hearing, collecting, interpreting and assembling narratives they are well aware of the interconnectedness of the lenses. As they do in their work, researchers may emphasis one or another lens or their intersections, or they may shift back and forth adopting the lens, depending on their specific approaches to empirical narrative material" (p. 658).

Therefore, to provide coherence or consistency I have chosen to:

- Convey the narrator's viewpoint and highlight the uniqueness of "each human action rather than their common properties" (Chase, 2005, p. 657). The narrator remains the central character and I as researcher have provided the 'supportive voice'

- Explore the "similarities and differences across the narratives" (Chase, p. 657), through story reconstruction using an 'authoritative voice'. This perspective of identifying patterns is a common feature of interpretive narrative inquiry (McQueen \& Zimmerman, 2006).

- Develop the narratives to meet a specific purpose and in this way, they are considered to be "socially situated interactive performances" (Chase, p. 657). In this project, the purpose is to provide understanding of the day-to-day experience of practice nurses.

The strength of this study is that the individual narratives and the connecting narrative offer a view of distinctive voices alongside larger collective practices of sense making and interpretation (Bamberg, 2007). The reality is different for each individual and the 'storying' is one way of preserving this. This reinforces the premise stated in the quote at the beginning of this chapter - that individual aspects and experience reflect social and cultural elements of life and therefore provide a basis for sharing of meaning and experience. The stories as a compilation give insight into the day-to-day experience of practice nurses.

Stories become narratives through the process of interpretation and analysis (Polkinghorne, 1988), and in this chapter, I have outlined the method and 
design of this study and explored the underpinning methodological principles used in this study. In the next chapter, I present five narratives as study findings and dimensions of nursing in general practice using the 'supportive' and 'authoritative' voice. These are representations, rather than representative of practice nursing. As the final stage of narrative analysis is the reading by an audience (Pellico \& Chin, 2007), and as this process becomes a site for further interpretation, the discussion provides further clarification and thinking to support ongoing understanding. 


\section{Chapter Five: Research findings - Dimensions of practice}

Understanding of one's own profession is also a tool for crossing boundaries between professions (Abrandt Dahlgren, Richardson, \& Sjostrom, 2004, p. 84).

In this chapter, five narratives are presented. To support the narrative voice I have constructed a connecting narrative to create a link between the individual narratives and as an interpretation of the significant parts. In keeping with narrative methodology that places value on the story format, a 'structure' presents each narrative as a whole - with a beginning, middle, and an ending. This format is based upon the prompts used in the interview format and therefore the storyline develops in relation to 'looking back' to starting practice nursing and the day-to-day experience and the meaning that surrounds satisfaction and challenge in everyday work. The narrative sequences are extracted from the transcripts and developed into the framework of the story and provide this perspective.

As noted in the previous chapter, I have presented each narrative with a quotation that links to a particular aspect of nursing. These quotations are sourced from journal articles and nursing texts specifically to support perspectives illuminated in the narrative. The use of footnotes provides the underlying description and explanation to support the story. In addition, footnotes ensure an uninterrupted flow within the narrative that would otherwise be broken by explaining terms and concepts. These provide the background to support the main narrative as it is being told and additionally highlights the day-to-day experience and meanings that occur. 


\section{Amy}

Community health nurses need to be very familiar with the populationcentred and individual-centred models of health. This is because they work with both models simultaneously...the population-centred model relates to objectives for the whole population...the individual-centred model relates to objectives for an individual client and the need to link the client to as many resources as possible, which will help achieve the clients' personal objectives (Edgecombe, 2006, p. 256).

For Amy, working in the community attracted her to practice nursing at the beginning of her nursing career as this enabled her to nurse in a way that fitted her personal nursing philosophy... "it was just something that was in the community, had this continuity of care".

After taking time out, Amy was back practice nursing and has now been working in one general practice for nearly ten years. Looking back, Amy can see that practice nursing has changed a lot from when she first began over 20 years ago. "When I first started I was doing a lot of triage ${ }^{3}$ work for the GP, I would do the recordings, take the history and other things like doing the dressings, and really all the sort of things required before and after the GP had seen the patients."

Today Amy's practice entails multifaceted primary health care nursing practice tailored to meet specific population and practice needs. Her day-today experience illustrates the nature of the role that she has developed, and shows how nursing practice develops and adapts in the general practice. Amy

\footnotetext{
${ }^{3}$ Triage work in general practice involves nursing assessment to prioritise need - either via the phone or as a person presents in the waiting room. The nurse makes an assessment and decides whether or not the patient needs: attention immediately; attention within 30 minutes, within one hour, later that day or the next day. In some instances, the nurse can take a history, assess vital signs and provide immediate treatment, and then involve the GP. Triage work over the phone requires the practice nurse to analyse presenting information, take a brief history and make a clinical judgment about the need for medical intervention.
} 
manages her time, workload and clinical demands to meet both individual needs and practice needs. She combines population health approaches (immunisation, education and management of chronic illness) with therapeutic and relational approaches to patient care. When asked to explain her daily experience Amy discusses the range of activities that goes on, the computer is switched on and then it just goes... you start off and you're looking at your appointment book, trying to evaluate who and why is coming in, and you think, okay so my day's going to be ... you might have vaccinations, ... or a diabetes check $^{4}$ and you mentally prepare yourself for what's hard and what is not hard. Then in between times you've got phone calls coming in saying, 'can I see you today?' So you've got to prioritise where it suits to fit them in, but where it suits them to fit in with what they want as well; that's the triage side of things. It just depends on what goes on in the day; like helping a lady with late stage renal failure, who didn't want to have dialysis and helping her through her terminal phase. Those sorts of things can take three quarters of an hour to an hour and maybe every week you are with [these] people and it's just not the vaccinations, it is referring through things to the clinics, things like that that take a lot of your time. [There is] a lot of diabetes education, asthma education, a lot of it is education. Even during vaccinations and doing well child checks, and talking to the mum at the same time, checking on their milestones, talking about post vaccination stuff, what the vaccines are for and then you talk to mum about her contraception - you discover those sorts of things by just going beyond the vaccine...there is so much going on... so you just can't predict it.

Amy's interest and knowledge in several specialist areas (youth health, sexual health and chronic care) have enabled her to develop a practice that works in collaboration with the GP and operates a nurse-led clinic $^{5}$ within the general

\footnotetext{
${ }^{4}$ With the increase in people with diabetes and with the funding changes in general practice, nurses have developed knowledge and expertise in annual diabetes review. Nurses are responsible for recalling patients annually, carrying out a full assessment that includes recording weight, blood pressure, a foot check, assessing chemical markers (e.g. glucose and cholesterol, kidney function) liaising with diabetes specialist nurses and GPs as needed and supporting any medication or lifestyle change.

${ }^{5}$ Nurse-led clinics operate within general practice to meet specific population health needs. The nurse organizes and manages the clinic, using current clinical evidence and protocols.
} 
practice setting. As part of this process, Amy works closely with the local high school to ensure that the students have access to nurse-led sexual health services. An important aspect of this has been to create a safe place that adolescents can come, discuss concerns and develop confidence in her as a provider as she explains.

We [the high school students and I] chat about unprotected sex or sexually transmitted diseases (STD) or things like that and it is really satisfying to be able to do STD check for them, and then they say 'oh that wasn't so bad after all' and they've got this discharge that you need to swab, and they get through it quite confidently, 'oh well, I coped with that', and then they go back and talk to their friends at school and you get more feedback...it's a privilege really.

Working with those of her community who need advice and support to manage their long-term conditions ${ }^{6}$ also plays a significant part in Amy's day. Again some of this work relates to her satisfaction working with adolescents to achieve improved symptom management but also reveals the needs of the population that are enrolled with the practice. Here she talks about working with young people who struggle to control their asthma symptoms and the use of their preventive and reliever medication (inhalers) in the most effective way.

I think you can just see these kids making a change. They go from being really really sick and then they will come back, talk about their inhalers and then they can start to see that maybe some of these things make a difference. Whether they use their inhalers for a short time or whether they get on to it permanently that it is their decision, but you are there to try and get them back and just remind them, it's nothing to do with what I want them to do. It's trying to work at where they're at...

Working relationally to support change and improve quality of life is a fine balance between supporting choice and providing just the right amount of information or motivation to help adolescents who often struggle to accept regular use of long-term medication.

\footnotetext{
${ }^{6}$ Any condition that has lasted longer than six months.
} 
As Amy explains, every day nursing practice involves assisting patients to make complex life changing decisions and may involve a focus on long-term change,

You [often] don't see change, but just get in and get stuck in and try and make a difference. You see success, and some losing weight and some [patients] just accepting the fact, like insulin, [the patients are] absolutely terrified but when you can actually give them the insulin (and) you've taught them how to use it (and they say) that wasn't so bad and they actually get control of diabetes that's cool. And it's things like helping somebody through their pregnancy when they really were unsure about it, what they were going to do and try and make some changes and helping them make their decisions about [what] they want.

For many patients coping with long-term conditions, any change in medication or lifestyle requires support and consultation time for education and explanation. For Amy this process involves having a thorough knowledge of the community and the ability to mobilise community resources. The capability of the nurse to investigate and use social and nursing networks and ensure that the patients can get the best care possible is important. This often involves a commitment to making the time but also advocating when there may be no clear clinical need.

You have also got to know the other networks that are out there as well; know [who] to refer people to. Nurses are good at knowing the social networks. The GP's know to call the hospital to call the registrar and sometimes that's about it. Nurses know to tap in to, who [to] refer to, and so it's that sort of knowing the networks in your area as well, and be a bit proactive... Nurses know when they've got to investigate or where to start to investigate to find something that is going to work, you mightn't know who to refer to but you know where to start and in that way you just weave your way through till eventually you find out.

Such processes of referral or connecting people with agencies or communitybased nurses such as district nurses, or other members of the multidisciplinary team, requires a broad knowledge and understanding of networks within the community. 
A number of nursing activities relate to the overall care of the patient and the smooth running of the practice. For Amy these activities combine with obligations to the greater practice management that involves daily and weekly responsibilities. Amy believes that clinical overview required in the process of recalls or follow ups ${ }^{7}$ enables a more comprehensive and timely service for the patient and at the same time ensures that the practice receives the appropriate funding for the nursing services:

We need to know whether the bloods are being done or do they need to have more bloods done and if this smear has not been ticked off properly all those sorts of things... if you do blood (tests) - lipids, diabetes (every three months) - it does need nursing input... making sure that the chronic care charges ${ }^{8}$ are done, the sexual health, the 'get checked' (diabetes) checks, we claim for all that and the antenatal.

Amy gains a lot of satisfaction from practice nursing work but finds that effective communication is at times constrained by language and cultural barriers. In addition, the current model of general practice prevents her from nursing in ways that would give her greater insight into patient needs and a real understanding of the dire circumstances that some people cope with when there is poverty and deprivation. As Amy explains...

Probably a big barrier is that we can't get out into the community, if we could actually get into homes somehow, and were funded, you'd actually see a different picture. I have been into one home and it was just a real eye opener to see that there was just nothing in the house and [the patient] had a loaf of bread and it was in the oven, just a plastic bag of bread sitting in the oven. It was just really very sad and to think I didn't really know that was how she was living...as part of our job then maybe we could make more of a difference and you could understand what [the patient's] whole life is all about. You could

\footnotetext{
${ }^{7}$ Many patients who visit the GP or nurse require some post visit work that may include referral, placing into the recall system, following up lab results, finding information or returning for such things as wound care management or education.

${ }^{8}$ To increase access to general practice the Ministry of health via PHOs provide extra funding for specific conditions such as diabetes, cardiovascular disease - this reduces the cost to the patient In some practices the nurses make these claims to the PHO on behalf of the doctor.
} 
provide more holistic healthcare and maybe do a diabetes consult in their home and you're on their turf and they can say 'well look at my cupboard I can't afford'.

Despite these constraints and in order to meet population needs more effectively Amy has advanced her own knowledge and skills through postgraduate education and to some extent paved the way for other nurses in the practice to extend their roles. Whilst developing, refining and defining her role within the practice she sees a range of nursing practice,

A lot [the other practice nurses] are day to day triage, and others are trying to find their specialties...but the doctors will often do a lot of that [sexual health]... it's still a bit handmaidenish.

This ongoing perception of nurses as handmaidens to doctors and the misunderstanding of the practice nurse role are at times frustrating.

They [other nurses in the community] know exactly that it is pretty hard going [but] at other times they still say that it's just a handmaiden job. [By] nurses doing postgraduate study, and doing other education, and starting to refer through to clinics and liaise with other nurses, [other nurses] have a good perception of what practice nurses are doing.

In addition Amy believes that there is a lack of understanding in the community about the role of nursing and the complexity and variety of concerns that bring people into the practice.

I think that people in the community don't actually realise... they think 'oh general practice, it's a nice cruisy place'. You go along and you get your pills and your potions, or maybe you have an accident and it needs suturing. Therefore a lot of people don't see what an acute [accident or medical emergency] involves, and they think an acute is a stitch or a miscarriage or something in the room and they [patients waiting] can see the ambulance taking off. They don't [often] think it might be somebody who just needs a bit of extra time to talk about something....

For Amy developing long-term relationships with people and being able to provide care over time is a significant part of the satisfaction in day-to-day practice. Associated with this is the ability to make connections with people and understand their social and family / whanau networks therefore building a 
picture of context and community. This helps to ensure that the treatment and care provided fits best.

I think mainly it really boils down to that long term relationship and having a really good knowledge of your patient base and the area that you are working in. I think this is probably extremely important because what works in one area doesn't work in another area and you need to use those connections, you need to start to realise that this person is connected to that person and if you want to get a message to that person then use those connections. The connecting with patients, I think those are the most important things, that is the essence of it. You have to show that you really do care, genuinely care; you are not just a nurse who does a task like an injection. It's all about relationships. 


\section{Beth}

Characteristics of partnerships are reflective of the way in which members interact to meet the common purpose. All partnerships include the establishment of a common purpose, clear role definition within the partnership, and respect as a valued partner" (MacIntosh \& McCormack, 2001, p. 550).

Beth's journey to practice nursing came after some years of travel...

I [had] practised as a midwife for a couple of years [but] I always had the feeling I wanted to work in the community rather than in the hospital, I took up an opportunity to go and work in a General Practice. I have not gone back to hospital work since!

Working independently and in collaboration with both general practitioners and nurses is something that Beth has valued over the years and this has influenced both her choice of workplace and her approach to practice nursing. She has been able to develop and focus on the specialist areas of practice within the general practice context with the support of a number of GPs for the last fifteen years.

Right from the start of my career as a practice nurse I was lucky to be working in a practice that truly valued and recognized the skills a nurse can offer general practice... by better utilising the nursing staff, patients could be offered more choice and received a better service.

Both the practice ethos and individual patient need influence Beth's day-today practice and she is particularly keen to with improve accessibility. Throughout the day, there is responsibility for workflow and practice readiness. ${ }^{9}$

\footnotetext{
${ }^{9}$ Maintaining readiness involves organising the treatment rooms, consulting rooms and other areas of patient - nurse / doctor interaction. It involves ordering and organising of supplies, resources and medication that is needed for a variety of nursing and medical functions. Maintenance of emergency equipment and supplies for the practice environment and the doctor's bags occurs regularly.
} 
We work from our own rooms, and I usually go in [on arrival] and check what is booked in for me. We also check our task lists, the receptionist may have sent you a note of someone that wanted to ring you, asked you to ring them or booked them in. Specifically we are allocated individual recall lists ${ }^{10}$ and throughout the morning you have to get time to check recalls.

A typical day can include cervical smears, sexual health checks, antenatal consultations, assessment for and after termination of pregnancy, dressing changes, contraceptive consults, hypertension monitoring, child or travel immunisations, ear syringes, accidents that need immediate appointments like lacerations, medication queries and repeat prescriptions. The [nurses'] clinics are set up to cater for women's health, in the gaps we do other things like immunization, (just) if there is an overload of patients wanting to get in or if there is an acute accident we deal with that. We are all responsible for ensuring stocks do not run low, and [that] the place is kept neat and tidy and cupboards are restocked.

As a part time employee, Beth works as the 'support nurse', a role that complements and assists the other nurse and general practitioner with their workload, but still provides an opportunity to manage her own patient load. She believes that opportunity to work as a team and draw upon the strengths of the whole team are vital to the success of the clinic. The GP's ethos has a part to play in the way that the team works together. Therefore, as she explains there is an emphasis on autonomous practice within the practice context.

[The GP] encourages and supports us to develop different areas so that different patient's needs are met, like one person specialises in diabetes and

\footnotetext{
${ }^{10}$ Practice nurses are responsible for recalling all patients for regular or timed procedures, tests and follow up. These may include recalls for childhood immunisations, a cervical smear, diabetes annual review, regular blood tests for anticoagulation therapy, cholesterol testing or blood pressure and weight monitoring. Recalls provide nurses with an overview of patient well being and are an important part of their health preventative and monitoring role as well as ensuring that the practice meets its quality targets. Recall lists may involve sending letters or making phone calls to hundreds of patients over a month. Many people do not respond to their first recall request so nurses are obliged to recall in some instances like immunisations and cervical smears up to three times.
} 
there are a couple of us doing women's health ${ }^{11}$ issues, because it is such a big area. Another one of the nurses is doing smoking cessation. Another one has a special interest and more knowledge on travel vaccines. So it means you all complement each other.

For Beth her knowledge and interest in women's and adolescent health are an aspect of her practice that she is able to maintain, even though she has a young family and works part time.

Women's health and youth health have always been a strong interest, working with the younger ones, adolescents who are making decisions regarding contraception or unwanted pregnancy and supporting them to understand their options and making an appropriate decision for themselves. [The environment] needs to be one that they would feel happy to come back to if they have any concerns at all... all patients need to feel they are being heard, and their needs both physical and emotional are being met by the practice as a whole.

The intricacy of nursing practice is illustrated in encounters that are meaningful but can be challenging. This process of working over time with individuals, listening and 'being there' for people is an important aspect of nursing work however these interactions are not always visible. Being able to support individuals through difficult times, give time and care is important for Beth and provides opportunity to establish and cement effective nurse patient relationships.

A young woman, early 20s, who came in and she had come for a little minor thing and we'd got talking about contraception and sexual health and sexually transmitted infection checks. She went on to make an appointment for a full sexual health check and all swabs taken came back normal. She made a further appointment to discuss these results there were quite a few minor things to sort out for her. The last time she came back to see me she said "Thank you so much for your time", and she said, "I feel really comfortable coming and seeing you...it is so much easier when you can feel comfortable with the nurse

\footnotetext{
${ }^{11}$ Women's health is an increasingly the domain of practice nurses as they are responsible for cervical smear taking, sexual health testing and family violence screening, hormonal contraception and emergency contraception as well as working. For many women being able to see a nurse rather than a male doctor has increased access to primary health care services.
} 
you are talking to, I felt silly saying some of the things I did but once we talked through it I felt okay'. When she said this to me it gave me a warm feeling, it had meant so much to her but I felt I was not doing anything.

There are a number of daily challenges in practice. For example, Beth talks about working with a young woman over a number of months as she made a choice about contraception whilst also managing difficult family circumstances.

She come back to see me several times and we would talk through concerns she had and different forms of contraception. She eventually decided on the combined oral contraceptive pill. I had real concerns [and] I made regular appointments for her to come and see me and she always attended. About 3 months after starting she came back saying she was finding it too hard to remember to take the pill and wanted to go on the Depo Provera injection. As part of the routine pre injection check we did a pregnancy test and unfortunately it was positive and she advised me of the other issues she was having to deal with....I did feel really challenged and really disappointed that I hadn't kept her safe from getting pregnant. But on reflection I know I probably would not have done anything differently and along the way I [had] talked [to the GP] about where we were at and so there was the back up ${ }^{12}$ there as well.

In instances like these, talking through issues is important and all staff have an opportunity to participate in mutually respectful interprofessional clinical support. In addition, the approachability of the GP and the use of computer messaging support the workflow, and sharing of information during the day supports optimal care.

The challenge of time management and the impact of maintaining effective patient care as well as productive interprofessional relationships are maintained in part through a culture of reciprocity.

You're often snatching time, like five minutes here or five minutes there. It always seems you need to finish work or go off for lunch or finish for the

\footnotetext{
${ }^{12}$ Back up in the general practice team can involve talking and reviewing practice with the other nurses and doctors.
} 
day... it means a lot to me because I know that the practice we work in is quite unique. I know that the staff relationships and the way [the GP] acknowledges and appreciates the work that we do are huge compared to some practices where nurses that aren't treated as well and their contribution to the practice is not utilised or appreciated. Because [the GP] supports us in the way he does none of us mind doing the little extra bits or having to stay on another 10 minutes to tidy something up or finish something off.

In addition, the practice as a whole makes a concerted effort to ensure that there is additional time for collegiality and support by holding monthly meetings and social events. Working as part of the team and using her knowledge and skill are significant aspects of Beth's day-to-day experience. We have some really constructive discussions during them [and] this means we have got to know each other. 


\section{Lisa}

Nurse's location within healthcare systems places them in a pivotal position in relation to other healthcare workers. Interface management and coordination of the work around patients emerges as a further bundle of tasks (Allen, 2007, p. 44).

Lisa's practice nursing began when she was at a career crossroads over ten years ago, "I was ready for a change so I actually got told about the position by a friend who was already working there, that's how I got into it really." Since then Lisa has worked in a practice located in a small rural town.

Although the physical surroundings are constraining at times Lisa, as the lead nurse, works hard to ensure that the day-to-day operation runs smoothly. From the moment that she walks in the door, she retains an overarching view, In the door, alarm, bags down, open the front door that is the nurses job, I' $m$ not sure why. That was at eight o'clock and we don't actually see patients until half past eight unless it was urgent of course. So just in that half hour we prepare for the day, sterilise the daily instruments and change the soaking solutions and those routine duties, do the fridge, ${ }^{13}$ get the doctors' rooms ready, make sure that everything is stocked, that type of thing. From half past eight to half past nine we usually take bloods, we spend a lot of time doing that, and the doctors start seeing patients at half past eight so we sort of get the flow from them if there was anything. Morning teatime is anywhere between 10 and 11 . So right up until then and in between then to lunchtime you have booked smears or booked in vaccinations, or booked STD checks or whatever. We work on a one to one ratio [nurse to doctor] but no set nurse to set doctor, if you have two doctors there we always try to have two nurses. ${ }^{14}$ We really try our utmost to do that. We have our work coming out from the doctors and in

\footnotetext{
${ }^{13}$ Cold chain management is an essential part of daily practice - nurses are audited by the Ministry of Health and responsible for ensuring that vaccines that are very sensitive to temperature change are kept in an optimal environment in the surgery fridge.

14 The daily workflow requires this level of nursing support - follow up for doctors is done in between nurse's own booked patients and triage work.
} 
between times, we try to do [other work]; my desk always seems to be the dumping ground for everything that is too hard. So, I work through that and then of course there is the task manager and provider inbox ${ }^{15}$ as well to work through, things like test results. We usually take sometime to sit down, usually after lunch, do the scanning and the paperwork and the recalls and anything else that needed doing. Usually I'd flick through that (the phone messages) in the morning and if there was anything urgent or if there was anything, anybody, that I knew wouldn't be home later or I knew worked or something like that, and having been in the practice for a long time I knew most people. In this instance Lisa prioritises messages and requests using her understanding of people's circumstances and lives to find ways that their needs can be accommodated best. As she further explains...

One of the satisfying things is the patient contact; you see people out at sports things with your kids and with their kids and everybody knows everybody... the patient contact and having worked for there for so long and having lived in the area, that was something that I enjoy. My passions were cervical screening [and working with] non-respondents. ${ }^{16}$ I have worked long and hard on that. When you really had to tidy up your practice systems and, the way you worked and the way you recalled people, it wasn't just about the nursing staff it was teaching the reception staff to do it as well.

Lisa's satisfaction at work is related to providing good workflow, an excellent service, and finding solutions to problems that arise. Ensuring that the practice met quality targets whilst still ensuring that there was effective service is a key

15 'Task manager' is a computer tool for keeping track of follow up work needed for individual patients and the provider inbox stores laboratory results and letters.

16 Within the recall system, the National Cervical Screening Programme requires that practices contact women who are due and overdue for their regular smear. Quality targets additionally relate to the percentage of cervical smears that a practice completes over a fourmonth period. Non-respondents are the group of women who have not responded to a letter or phone call regarding their need for a cervical smear. Thinking creatively to find ways to encourage women to have a smear may involve working outside normal clinic hours, accessing funding to reduce cost or spending time talking to women about the importance of this screen procedure. 
element of Lisa's role as well as having a strong commitment to practice and the population, particularly in relation to cervical screening as she describes;

I used to run smear clinics - I would come in specially on one of my days off and do 12 smears and work to get yourself into a system that works...when we ran the smear programme providing a free smear for women that were overdue, who had never had one or whatever. That was hugely satisfying and the women get off the couch afterwards and they say 'there was nothing wrong with that, that's not so bad, I'll be back next year', and just taking the time to speak to those as well that wanted to speak... and then just seeing the percentage rise as a result of that...

In addition working alongside the doctor, supporting case management ${ }^{17}$ approaches and liaising with other nurses in the community are aspects that provide satisfaction and challenge.

I also work a lot with the rest home. It is usually me that goes with the doctor out to do the rest home routine visits and the palliative care as well ${ }^{18}$. I work really closely with the district nurses and hospice and things like that. Just making sure that everything [was in place for the patient].

At times, the business model of general practice creates conflict for nursing practice. Lisa has witnessed this amongst the nursing colleagues that she works with and those she interacts with in other practices. Working in a feefor-service environment nurses often find it hard to charge people a fee. Lisa now believes it is important for nurses to consider both the value of nursing work alongside the business aspects of general practice. However, at times Lisa struggles with this concept as she discusses...

It used to be practice nursing was all about the patient, but going into a managerial role, you've still got that patient thing going on but trying to do it

${ }^{17}$ Care coordination or case management requires nurses to ensure that assessment, planning and referral to other services are actioned and that the best outcomes can occur for patients. This might involve working over time with social workers, specialist nurses, district nurse and liaising with the doctors to ensure that intervention, medication and other requirements for patients are met.

${ }^{18}$ In many areas, GPs have a relationship with local aged care facilities. This means that nurses accompany the doctor when they visit to provide support. Nurses will also home visit with the doctor or alone to assist families at times of palliative care 
from a business perspective at the same time and that's really difficult for nurses, especially new ones. Often they don't understand that general practice is a private company, it's a business and they are there to make money at the end of the day, provide a service, and that's quite difficult for some nurses, especially if they have come from a public sector. When nurses provide a really good service, a more than adequate service, but [are] not charging for it, that kind of works against them in a way. Then they're wondering why the doctors are wanting to make cuts. But they've got their caring hat on, and that may make me sound hard as a nurse but it's where I've come from recently, I've had to try and envelope the whole lot in together while still providing the great service.

One of the big issues is time or lack of it, so for Lisa creating ways to manage everyone's needs is a times a struggle, but she manages the day by planning ahead and ensuring that there are enough staff working to cope with whatever is planned and unplanned.

Time is the biggest thing ... there are times when you open your appointment book in the morning and they have got you booked solid. You know you've got no time to do anything else... and patients have expectations that don't often fit in with the appointment system. I instigated a system where each doctor had nurse appointments [during] the day and the nurses were the only ones allowed to book anything in those slots. I am a very firm believer in if someone comes in off the street, unless they had to be seen then, you take the next available nurse appointment. And if the nurse appointments were full then you started triaging a bit more.

Managing patient flow in between appointments can be especially challenging. In a small town particularly there is often no other accessible GP the nurse negotiates with the doctors and juggles appointments to make sure that everyone can be seen. The skills of both assessment and advocacy are important here. However, in this busy environment Lisa is very aware that sometimes things can get missed, therefore she makes time to double check and plan ahead.

"If you're rushed and doing that sort of thing then you make mistakes and everybody is human and they do make mistakes and if the doctor has already 
missed something when they have read the letter ${ }^{19}$ which more often than not happened then it got picked up at the sorting [by the nurses]. [And] just being able to sit there and look at your day - the first thing I ever did was look at the appointment books, for example I'd look to see where there was an immigration medical ${ }^{20}$ and check whether it was booked at morning tea."

Developing skills and practice systems to deliver an effective service for a complex rural population is an important part of Lisa's day-to-day experience. Managing competing expectations of patients, staff and the business is a large part of this. Lisa's story illustrates the comprehensive overview work that goes on behind the scenes.

I think the time management is important and the funding and you know not necessarily the funding from external sources, from $\mathrm{PHOs}^{21}$ or anything like that but that's great to be able to do those projects. Yes, it has made a difference, and that's where it comes from - you know you are providing a service from here [your heart].

\footnotetext{
${ }^{19}$ In some practices, the nurses are responsible for reading the mail, scanning in letters into the computer and following up results. This may be complementary to the doctor and enable the nurse to keep up to date with patient information and therefore be able to answer questions, provide support or make referrals to other nurses in the community if needed. It can be a way of saving the doctors' time by sorting correspondence that needs clinical follow up or prioritising workloads.

${ }^{20}$ Immigration medicals involve both nurses and doctors and can take up to an hour to complete, particularly if more than one family member is involved and language is a barrier.

${ }^{21}$ PHOs or Primary heath organisations have been able to provide funding in different ways to meet specific local needs.
} 


\section{Molly}

Nurses in all types of practice stand at the intersection of clinical and administrative needs (Thomas Hegyvary, 2007, p. 104).

Molly's story of practice nursing began over 30 years ago when she worked as part of a programme that sought to include nursing in general practice. As Molly recounts, "I worked extensively in the hospital, but I didn't really like the hospital, I like working with the community." Since then she has worked as practice nurse in range of communities and in other community nursing roles. This has led her to her current role, which involves working in a clinic governed by a trust. Molly has helped to set up both nursing and administrative functions to support the medical roles as she explains, "There were two nurses doing the job I'm doing and they were combining that with sort of outreach nursing, ${ }^{22}$ so I basically had to start off from $\operatorname{scratch}^{23}$ [and] do a lot of tidy up time."

Molly's long association with practice nursing has meant that she has seen a number of changes and developments occur. Nowadays nurses can lead clinics to meet specific needs but at the same time, this development depends on a level of trust between the GP and the nurse.

You have to prove yourself... I think we are lucky in that we can run our own clinics with GP support, do the hypertensive clinics, diabetic clinics, asthma clinics, we can do our own cervical smears and we are given a lot of autonomy and of course the GPs are there if we need any back up.

Molly's current place of work and her previous experience of practice nursing and the requirements of the practice population determine the nature of the current position. In addition, as an establishing clinic with two part time

\footnotetext{
${ }^{22}$ Outreach nursing involves nurse's home visiting in response to referrals to carry out chronic disease management.

${ }^{23}$ Developing a practice involves considerable time developing protocols, processes and systems to ensure that population needs are met and funding is forthcoming, particularly in relation to clinical outcomes such as disease coding, identifying the percentage of smokers in a population or immunisation rates for children. The $\mathrm{MOH}$ sets targets for these clinical outcomes.
} 
doctors and one nurse, the nurse works longer hours than the doctors do. As the only nurse in a practice that is starting up means that Molly has a wide range of responsibilities and she therefore spends part of each day as the sole health practitioner on site.

Molly's day starts with a meeting with the practice manager before the medical staff arrive and this is a time to discuss and plan and then,

I open up my own office, the doctors' offices, get the computers up and running, help out in the office, making appointments and when the doctors come in I go into my own office and become the practice nurse, and there always seems to be a lot to do, babies who are sick and a lot of phone calls.

Once the doctors leave for the day, Molly continues to be responsible for phone calls and anyone that comes into the clinic,

Being an ACC provider ${ }^{24}$ I can also do a lot in that area, I tend to mostly listen to what they are saying and then, suggest that they go into our after hours doctor. The accident today, a woman came in, she trod on a rusty nail yesterday and [wondered] when did she have her last tetanus and I said that there is no record of it so she is best to get herself here. So I was able to do that whole thing, dressed it... Or 'I have a got a fish hook in my finger, what am I going to do?' Then kids with burns. We get a few of those.

Therefore at present, Molly is triage nurse, venipuncturist ${ }^{25}$, vaccinator, and smear taker, and responsible for all other nursing functions and triaging when no doctor is available.

I am answerable for any decision that I make, most of the doctors we can contact by phone or the pharmacy or something like that, so it's not too bad, but I take that responsibility."

\footnotetext{
${ }^{24}$ As ACC providers, nurses are able to claim a fee from ACC for provision of treatment they provide. They can see and treat minor injuries without having to wait for a doctor to oversee the process.

${ }^{25}$ Venipuncture (or taking blood from a vein for testing) improves access to diagnostic testing for patients at the place of consultation.
} 
In addition, she makes herself available to support the other staff with receptionist duties and checks clinical notes daily to ensure that all the patient classifications ${ }^{26}$ are completed by the doctors, thereby ensuring that practice targets are met,

Apart from my role, you know, I'll help out on the front desk if they're bogged down or relieve them for lunch as they don't actually get a lunch break and no we just actually work in together. They ask me and I ask them. It's a good relationship.

In many instances, Molly works closely with the GP and other specialist nurses in the community. Being able to develop relationships over time with the local people is an important part of her nursing although the nature of general practice has changed some aspects of this continuity.

I miss seeing those women through a pregnancy and with the delivery you know and then we don't see the babies until they are about six weeks old.

However Molly has been able to retain her interest in aspects of nursing that she most enjoys,

My passion is women's health... it is perhaps getting a reluctant person up on the couch and getting those smear results which are not good like CIN $3,{ }^{27}$ and the thought that maybe because perhaps I have insisted a little bit or been very firmly encouraging and the possibility that you know you have perhaps been instrumental in saving someone's life, or, from further development of carcinoma in situ those are... and of course the mammograms with an early breast cancer is detected. I'm quite passionate about that.

Whilst utilising her previous nursing experience Molly has also developed strategies for support and liaises with other nurses to enable her to work as the sole nurse. Previously she worked in a team where the nurses all had different

\footnotetext{
${ }^{26}$ Classification of disease or disease coding is carried out in order to develop good clinical documentation but also for the analysis of population health data.

${ }^{27}$ Cervical intra-epithelial neoplasia is a condition in which there is change to the cervical cells that may develop into cancer. This condition requires specialist intervention and treatment.
} 
specialties and were able to expend their knowledge and expertise in certain areas. In many ways, practice nurses are expected to have both generalist and specialist skills and rely on informal and formal networks to provide education and support.

This is the first time I have ever worked alone, I have to say, I have always worked with a team of nurses and having all specialists, say the diabetes nurse and the travel vaccine nurse, and this that and the next nurse. I have always concentrated on the cervical smears and mammograms, now I find it is quite onerous being on your own. However I liaise with our two outreach nurses [and] I rely a lot on the community outreach nurses for chewing things over with and one of the nurses from another practice agreed to be my mentor ... although the practice hasn't actually come up with the funding for me to do this yet. I work with the Diabetes Educator Nurse and the Asthma Educator so, I get the people into their clinics basically and we all support each other, [For example] we have about three palliative care patients, and I work in with the hospice nurses and the GP. "[There are] monthly practice nurses meetings and education days.

Molly concludes:

You have got to be prepared for the extra, the extra incident [but] I have been blessed with this job. 


\section{Penny}

Working in partnership to guide people is among the greatest sources of professional pride, yet often this aspect of the role is not well articulated. Nor is the role of the nurse as resource person, using expert knowledge as a guide to client empowerment (McMurray, 2007, p. 34).

Penny started practice nursing after she was offered a position by a GP that she had previously worked with in the hospital setting. She has since worked in the same practice for a number of years. "Hours I think was the main draw card. I had only worked in a private hospital so I didn't know what it was; I just wanted to do it."

Working in a large urban practice the nurses are employed by the practice however each works with a specific GP. Penny has worked with the same GP for a number of years and together they have adapted their practice philosophy and service systems to meet the needs of their enrolled population.

Penny's account of day to day practice portrays variety and complexity and, a way of working that fits the individual styles of the practitioners and the population priorities and needs.

First thing is to make a coffee [and then] look [to see] if there are any messages to get back to. Turn on the computer to see who is coming in. The GP [that] I work with in the practice, we work differently to the others. Most of our patients don't make appointments. They can come in the morning, it looks quiet, but by the end of the day you are going 'oh my'! I look at who is coming in to see if there are any due for anything else other than what they are coming in for. ${ }^{28}$ Then into it, I mean you have [people with] dressings ${ }^{29}$

\footnotetext{
${ }^{28}$ Checking to see that people are due for anything is an important role that many nurses carry out, this involves checking the recall system and clinical record to see if there are any procedures, tests or immunisations that need to be carried out. Doing this when people are at the doctor may save the patient time.

${ }^{29}$ Dressings - these can be daily, weekly, for re-assessment or related to infection, excision, or accidents.
} 
coming in [and those wanting] immunisations ${ }^{30}$ walk through the door. I didn't do any smears today but I did two cardiovascular disease risk assessments ${ }^{31}$ and I do diabetes "get checked", take [more] messages, do prescriptions, audiograms, scanning, but I'm trying to get that changed, also we do plastering. [Although we have a sign that says A \& E], we have registered patients that walk in and if they walk in and we're full up with casual patients they can't see a doctor, [so it's important that] the receptionists are able to space these out. My job at the beginning of the week is to make sure that the oxygen cylinders are full, during the day there is the cleaning of all the instruments, speculums, results and [checking laboratory results] phoning up patients with their INR results, ${ }^{32}$ sending [results] letters out. I haven't quite taught my doctor to send his own letters [and] if I do a cervical smear for [the other GPs], I send out the letters.

Penny works with high needs population ${ }^{33}$ using a number of decision support tools on the computer that enable effective and accessible alongside provision of continuity of care. An important aspect of Penny's work is developing relationships with families and individuals whilst providing care that is both preventative and restorative.

"Sometimes [the patients] don't actually come in for a medical reason... [and] you do build up a rapport with your patients; they trust you a lot more. You know a bit more about who they are and they just like to be heard. The old

30 The process of immunisation involves health education, gaining informed consent, supporting the parent / caregiver and child and adapting practice to the different ages and stage of the child. Often the nurse may need to work out how many immunisations have been given and then what is needed to catch up. This involves planning the next steps with parents. Parents need support and reassurance and information about what to do if their child is unwell post vaccination.

31 Cardiovascular risk assessment involves a comprehensive assessment, history, patient education and intervention to reduce the risk of cardiovascular disease and therefore events such as heart attack and stroke.

${ }^{32}$ Management of anticoagulation therapy requires regular blood tests (referred to as INR tests), interpretation of results and adjustment of dosage as needed.

33 High needs population - those populations who have low incomes, live in remote locations, have complex conditions, and may not access GP services readily, Maori and Pasifika peoples. 
people, sometimes you're the only contact they have had... and I tend to walk around cuddling babies a lot. They like that, I like that... when you finally get that child who is overdue for immunisations, and then it is a good feeling, supporting a woman to have a smear who has not had one for a long time. I wouldn't be in the job if I didn't get job satisfaction most days. It can be just a smile from a kid who comes in crying with blood dripping down, needs sutures and a dressing and who you have helped to make feel better.

Working alongside individuals over a period of years can involve helping them to become knowledgeable and able to manage to their chronic condition and make then lifestyle changes to improve health,

Over a period of three years you learn everything, you know, the family, educating patients, and this one guy he's very overweight and diabetic, everything is wrong with him. And this year, life turned around...he started with the District Health Board programme, as well as working with me and it's just with each other, collaboration. He has achieved so much in a short time, worked to get fit. It's just perseverance. So it was two angles fitting in, ${ }^{34}$ because it's not me, because ultimately they're doing it, it's their lifestyle change. It actually gives me a nice big 'buzz'. Especially after going through a hard year, that's paying off. Seeing the differences in patients, understanding a bit more when you talk to the hospital, there is not enough collaboration though, between the clinics. And the cardiovascular risk programme, they [the patients] come in three monthly for reviews with me and they don't need to the GP [every time]. Just talking with them, educating, listening.

However, there are barriers and some conflicts to improving outcomes that Penny finds frustrating at times; for example, the funding formula has reduced accessible and affordable services to some of their community who are on low incomes.

\footnotetext{
${ }^{34}$ Lifestyle change often results from a number of factors contributing to change not just one action or circumstance.
} 
Funding...because we do have patients who are richer, our patients who aren't [well off] lost out big time [with lack of extra funding] and still do. ${ }^{35}$

In addition, Penny would like to see more funding available to support nurse led initiatives and a wider range of services such as home visiting.

Working with the other nurses is important however there are a number of issues as there are individual work patterns and despite the size of the practice there is no overview nursing role. Sometimes it is difficult to organise care so that all needs are met.

Appointments can be anything between 10 minutes to half an hour... if they [the receptionists] are booking appointments for me, no matter what they are, it's a half an hour gap, even if its immunisation and such, not necessarily that that's how long it's going to take me but because there is always someone that walks in that [might need something] like a dressing. A couple of mornings this week I have had one patient after another for about two or three hours.

Consultations may take longer than expected and she tries hard to plan for this eventuality. Penny believes that it is important to take the time needed to maintain and establish relationships while thinking about the wellbeing of the patient and the whole family.

When you are talking to the family you pick up on scabby sores on the other kids or ask Mum are you overdue for a smear? Can we do that? You are just looking for anything; checking the files [and] update[ing] patient details. You're talking, you're listening, and you're there. They ask advice and sometimes you notice [things]. I picked up on a baby with a problem [and] she did need referral, [as] no one else had picked it up, [even though] another doctor had done the six week check and another nurse had vaccinated, yet there was something that

\footnotetext{
${ }^{35}$ One of the dilemmas of population health funding is that as it is based on geographical coding in some instances people can be disadvantaged because even though they have low incomes they may live in an area that is regarded as middle to high income.
} 
was just wasn't right. I do a lot of triage in the waiting room, a lot of visual $^{36}$ and I go and sit down in the waiting room and talk.

For Penny, developing relationships, having perseverance and receiving appreciation from the patients and the GP that she works with help her to get through the day and gives value to the practice nurse role. With involvement in postgraduate education she has further been able to develop and extend her practice to meet specific population health needs.

You have to have a passion for your job. If you don't, you'd leave. That's the most important thing, have a passion. Some days you drag your feet to work but that's normal. Most days I go in there smiling, I might walk out dragging my feet most days but I have a passion for my job and I have got an amazing reference from my GP, and that's nice, when you get [that feedback].

\footnotetext{
${ }^{36}$ Observation and assessment is a key skill of health professionals - watching over patients in the waiting room is one aspect of practice nursing that is overlooked. This key role means that any potential crisis is averted or patients can be seen in a more timely fashion.
} 


\section{Connecting narrative}

Life does not stand still; it is always getting in the way, always making what may appear static and not changing into a shifting, moving, interacting complexity (Clandinin \& Connelly, 2000, p. 125).

The practice nurses in this study started their nursing career in a hospital setting and were attracted to nursing in general practice for both the opportunity of regular hours and a desire to work in the community. Day-today experience varies due to the different work environments, employment relationships, communities and populations.

The computer goes on and the phone starts to ring. Consultations and encounters with patients range in length and variety. There is a need to expect the unexpected. The nurse therefore plans for the unforeseen and tries to make time available for these events or happenings. Each day nursing time and activities meet different needs, works with a range of age groups and health professionals.

Being available in between appointments is an important part of the day-today work - to follow up work for GPs or from previous days work. Phone calls may require an immediate response; others are for information, advice and requests for prescriptions and laboratory results. Practice nurses work in booked consultations and in response to patients who drop in or emergencies. They triage on the phone and in the waiting room and keep an overview of what is going on to facilitate workflow. In the gaps or whilst snatching time both the unexpected and routine aspects of work are managed. Day to day experience includes maintenance of the environment; preparation and checking of equipment and supplies, quality activities and the administrative work that surrounds recall processes.

The nursing time with patients is often filled with conversation and inquiry about life and health, and aims to encompass both restorative and preventative 
care. If possible, taking extra time during an appointment for such procedures as an immunisation or a cervical smear provides opportunity to discuss any issues that may be of concern and to establish rapport or extend existing relationships. In the day-to-day practice, nurses looks beyond the routine and anticipated outcome towards an understanding and support of the lived experience of the patient or family.

Within general practice, nurses have taken the responsibility of provision of preventive care and screening. These processes may be tied to quality targets and often involve clinical overview to ensure that the patient is not inconvenienced. It also involves thinking about ways to engage patients in screening opportunities; these may be opportunistic or systematic. Making a difference can be realised here, meaning and value are attributed to meeting practice targets and achieving preventative care or working with a patient or family over time to support lifestyle change, medication review, or engage with a preventive measure such as cervical screening, immunisation or risk assessment.

Practice nurses use community networks to ensure that their patients are able to access other services for advice and follow up. These networks include having knowledge of specialist nursing roles and community resources and being able to advocate for patients and families. Some of these networks are informal - some are more structured. They value the relationships that they have with their GP colleagues to support the intricacy of medical care and knowledge required by patients.

Alongside long-term relationships with GPs, practice nurses value the length of time spent in one practice context as they see that this supports their ability to meet the needs of the communities and develop effective ways of working with colleagues and the community. There is a focus on being able to provide continuity of care and being available and responsive when change or crisis occurs in people's lives. 
Challenges are managed in informal ways but may be influenced by workplace relationships and affected by inadequate resources or the business model of general practice. Working autonomously and within registered nurse scope of practice involves having effective and supportive relationships with doctors and nursing colleagues; however, these relationships are dependent upon the goodwill of both parties and less on formal processes such as regular team or clinical meetings . Lack of appropriate funding for patients, barriers to nursing mobility and different models of care coupled with a lack of understanding and compensation for nursing work add to the tensions and challenges.

Tension may involve not being able to provide the best care at certain times due to busyness or work demands, or may be the result of the complexity of illness or patient circumstances. Managing the workload and booked appointments is a daily challenge. Mediating different patient needs requires an overview of the day alongside the ability to negotiate doctor and nursing time to meet expectations. This may involve managing the appointment book to make space or negotiating with the doctor to see patients who arrive unexpectedly and require urgent attention. It may also involve negotiating with patients to keep waiting times at a reasonable level.

In particular, understanding the lived experience of patients and the community; working collegially; the provision of both continuity of care and preventative care, alongside the management of complexity together with adaptability and working autonomously give meaning to the day-to-day experience of practice nurses. 


\section{Chapter Six: Discussion and final conclusions}

Much nursing practice consists of acts needed to endure crises rather than resolve them. The care itself and the issues that nurses deal with (pain, fear, physical incapacity, complexity and risks presented by drugs and equipment needed for treatment) are reminders of the vulnerabilities in the human condition. Until individuals are confronted with the need for nursing care, many are unaware of the knowledge and skill involved in managing all of these elements (Clark, 2007, p. 177).

In the previous chapters I have explored contextual and personal positioning, discussed current thinking and research, and, presented the methodological, and design processes used to construct the narratives of five practice nurses and represent these by the connecting narrative. I have identified that there is limited research on the day-to-day experience of practice nurses in New Zealand, which contributes to a lack of visibility and a clear understanding of practice nurses' day-to-day experience. In this chapter, the findings are analysed through connecting commonalties and tensions alongside the limitations of this research project. As previously discussed, the narratives speak for themselves to make sense of dailiness and audience interpretation will create new perspectives. I believe that the target audience is anyone who has an interest in the sustainability of nursing and quality patient outcomes in general practice.

The narratives within this study illuminate dimensions of nursing that align with the principles of the PHCS. Participants value and work to foster effective nurse-patient relationships; in doing so they support access to services and constancy of care. Furthermore, whilst working in general practices they develop comprehensive knowledge of individuals, families and the community that they work in. Day-to-day experience illustrates the multiplicity of activities and innovation used to negotiate boundaries of health concerns and business requirements. Value is attributed to autonomy in areas 
of interest or specialty and these aspects are dependent on collegial relationships.

In summary, there are three main themes made visible within the narratives and two minor themes. The main themes are the significance of nurse-patient relationships and the fostering of continuity of care; the adaptability of nursing practice whilst managing complexity and unpredictability and the importance autonomy and specialty primary health care nursing practice. Related to these concepts is 'knowing' the community and the value of collegial relationships.

Alongside these themes, tensions are highlighted. These tensions can be connected to the context and history of general practice in New Zealand, traditional perceptions of nursing in general practice and the increasing demands on nursing, alongside an uncertain professional career pathway. To counter the tensions that surround practice nurse work within the public and general practice arenas nurses need to shake off traditional functions and perceptions as assistants and handmaidens or quasi receptionists. A clear understanding and forthright articulation of the nature of work in this context is required if nursing is to realise its potential.

Aligning work to the principles of PHC provides one lens that demonstrates value and worth. Therefore, the lens constructed in this chapter again uses the 'supportive voice' in conjunction with the principles of PHC. These principles focus on service accessibility, affordability, acceptability, and first point of contact care that is both responsive to and reflective of community needs (Magnussen, Ehiri, \& Jolly, 2004), alongside a PHC nursing ethos that is responsible for promoting, improving, maintaining and restoring health (Expert Advisory Group, 2003). To support the discussion of themes, excerpts from the narratives emphasise the connections within the experience and meaning and literature is considered to support emerging ideas. 


\section{Nurse-patient relationships and continuity of care}

As Lisa states, "one of the satisfying things is the patient contact; you see people out at sports things with your kids and with their kids and everybody knows everybody." Nurse-patient relationships are a source of pride and satisfaction but become challenging when perceived as ineffectual or are constrained by external factors and circumstances. At these times of uncertainty, participants were dependent upon colleagues and informal processes for ongoing support. Nurses look back on successful relationships and keep relationships at the forefront of their day. As Weinberg (2006, p.37) suggests in relation to her research into nursing roles in hospitals the ability to form relationships is crucial to being able to assess and plan care and "provide[s] a vehicle for gathering rich information about patients". Therefore, the nurse engages in discussion with patients to develop partnerships that rely upon understanding "all that is going on for the individual, family and community" (Jonsdottir, Litchfield, \& Pharris, 2004, p. 243). However, Allen (2007) notes that while the "nurse's status as information broker means that they have a key role to play in shaping the outcomes of care; yet the value of this contribution is rarely made visible" (p. 45).

The concept of continuity of care is illuminated in this study and can be summarised as informational, management and relational continuity. Informational continuity relates to the judicious use of knowledge about a patient to configure appropriate patient. Management continuity is an approach that organises individual care and lastly relational continuity refers to the committed and longitudinal relationship between a patient and one or more providers (Haggerty et al., 2003). Notably the participants placed emphasis on continuity, particularly in relation to chronic care and family health, in effect responding to community need. However, they did miss aspects that had once enabled increased continuity such as antenatal and postnatal care.

In the past general practitioners have been perceived as the main providers of continuity particularly in relation to improved preventative care, quality in 
chronic conditions, management of psychosocial concerns and for certain age groups (Gray et al, 2003). These narratives illustrate that nurses have a large part to play in this aspect of general practice. Most importantly "evidence suggests that continuity of care improves the uptake of preventative care, enhances adherence to therapy and increases patient and physician satisfaction" (Rosser \& Schultz, 2007, p. 1385), access to preventative care being a basic tenet of PHC.

In the fee-for-service environment of general practice, time taken with patients comes into conflict with the time needed to complete tasks, substantiate value for money and meet patient expectations. Lisa's solution to this dilemma is for nurse education to provide a broader perspective of health economic issues, "somewhere along the lines of business management might be a good idea", so that nurses can reconcile the business aspect of general practice. On the other hand Beth highlights the importance of "funding free sexual health appointments for under 24 year olds has made people feel that they can access us easily". In this way Beth is able to provide an effective service without feeling constrained by charging fees. These ideas reflect the ambiguity of nursing in general practice as the nature of fee for service and targeted population approaches operate as conflicting standpoints.

There is considerable skill involved in engaging in meaningful relationships with a number of people in one day. By not articulating the importance of relationships, there is a risk of losing a constant nursing presence in general practice. This is particularly relevant if delegating medical tasks to other groups such as physician assistants. In addition, ensuring that this strength of PHC is not undermined by constant change is important (Ashton, 2005). As Boyd (2004) emphasises, the importance of relationships and time is necessary to sustain effective chronic care management, particularly as the "nurse becomes the interpreter of the vast complexities of chronic illness care through this relationship" (p. 9). As discussed previously financial constraints mean that the caring and relational practice is in danger of being misunderstood or remaining invisible - possibly by nurses themselves. 
Liaschenko and Peter (2004) suggest that "housekeeping issues typically involve relational work, which is work over time in on-going relationships" (p. 490). However, due to the perceived task nature of some nursing activity this type of work remains invisible, for "it would seem that task-orientated activities lack the moral status of caring or presence that are articulated as internal goods of nursing" (p. 492). Again, the challenge is for nursing to consider itself as a profession and therefore articulate the interrelated components of nursing work (Allen, 2007). These narratives begin this process by illuminating the aspects of dailiness or the routine aspects.

\section{Being available and managing complexity}

Day-to-day experience illustrates management of complexity and unpredictability within time constraints. All the narratives talk of needing more time to carry out nursing activities. As Beth states "you're often snatching time, like five minutes here or five minutes there." Day-to-day experience encompasses a breadth of work, influenced by individual patient need and quality, alongside practice priorities that align with primary and secondary prevention. Participants managed workloads by working in different ways and negotiating with administration staff to manage unpredictability and maintain accessibility. As Penny says, "sometimes [the patients] don't actually come in for a medical reason" and Beth notes, "our role is to see anyone who walks into the clinic without an appointment, but needs to be seen".

Complexity and availability is evident when others work differently or if the nurse organisation of changing patient flow comes into conflict with scheduled appointments. Therefore, coordinating appointments, asking other staff to change or make space, constant checking and inquiring are dominant concerns. As Lisa states, "my desk always seems to be the dumping ground for everything that was too hard," illustrating the work that goes on behind the scenes. Amy suggests that "a lot of people don't see what an 'acute' [accident or medical emergency] involves, and they think an 'acute' is a stitch or a miscarriage or something in the room and they [patients waiting] can see the 
ambulance taking off. They don't [often] think it might be somebody who just needs a bit of extra time to talk about something." Allen (2007, p.45) considers this the work of "prioritizing and rationing resources" and vital to patient well being.

Nursing in general practice often involves the negotiation of two workloads that of the nurse and that of the general practitioner. In the participants' experience and as Lisa comments, "we have our work coming out from the doctors and in between times we do our other work," or as Molly finds, "I go into my own office and become the practice nurse." It is worth noting that Weinberg (2006) found that nurses have a propensity to change their work patterns and increase their workloads rather than confront the actual structural issues. As Lisa notes "I used to run smear clinics - I would come in specially on one of my days off" or Molly who tells us that "apart from my role, I'll help out on the front desk if they're bogged down or relieve them for lunch as they don't actually get a lunch break". The participants believed in providing the best care possible and were all prepared to adjust their day and negotiate with other practice members to ensure that patients' needs were met. Therefore they were in fact filling gaps and contributing to the invisibility of their own work. As Beth summarises, "[The environment] needs to be one that they [the patients] would feel happy to come back to if they have any concerns at all."

Interestingly nursing availability and flexibly in general practice has been constructed as a commodity for general practice (Phillips \& Dawn, 2007). For Lawler (1997) the concept is of far more import.

Availability is a perceived and intangible phenomenon that relates not only to the physical availability of the nurse, but also an emotional, personal, existential availability in which patients sense that the nurse is there for them - as the embodied and vulnerable other who needs protection, reassurance and support. These are things that lie outside the discourse and modalities through which economic understandings are formalised (p. 48). 
Therefore, working with patients who have complex needs and in an unpredictable environment, while remaining available, is an activity that supports the implementation of PHC principles in general practice. However, it is a concept that is poorly recognised and at odds with economic imperatives.

Complexity is not a new concept in general practice, and often relates to complicated patient situations (Heath, 2004; Love, 2004). However, in the participants' narratives, complexity is evident in both clinical situations and within the elements of nursing that Allen (2007, p.43) describes as, interrelated bundles of activity - managing multiple agenda, circulating patients, bringing the individual into the organisation, managing the work of others; mediating occupational boundaries; obtaining, generating, interpreting and communicating information; maintaining a record and prioritising care and rationing resources.

Or as Amy illustrates: "even during vaccinations and doing well child checks and talking to the mum at the same time, checking on their milestones, talking about post vaccination stuff, what the vaccines are for and then you talk to mum about her contraception - you discover those sorts of things by just going beyond the vaccine...there is so much going on... so you just can't predict it."

\section{Autonomy and specialty}

Being able to work autonomously and realise specialty aspects was an important aspect of day-to-day work. The participants placed value on their ability to be able to work with individuals and families to foster change, inquire and investigate to ensure that all avenues were explored to implement the best planned care. Making life a bit easier, allaying fears or taking time with patients were important aspects of work and a source of satisfaction. The small things that the nurses did were seen as valuable as the more exciting aspects of practice. Increasing access, preventive and restorative care was 
therefore enabled by specialty and autonomy such as interest and enthusiasm for youth health, women's health or long-term conditions.

Participants often watched change occur over long periods but were prepared to be persistent and wait until patients were ready to take the next step. As Amy believes, "I think you can just see these kids making a change. They go from being really really sick and then they will come back, talk about their inhalers and then they can start to see that maybe some of these things make a difference". What is evident in these narratives is that practice nurses have successfully created interfaces to meet population need by developing specialty. However it is worth noting that the in UK nurse-led clinics specialist roles tended to create uneasiness in environments where there was little expectation that nurses worked as colleagues (Gibson \& Heartfield, 2005; Willis, Condon, \& Litt, 2000). This reinforces the need for clarity for as practice diversity can make development complicated. However these narratives illustrate that diversity is reflective and responsive to population need.

Irvin, Sindani and Hall (1998) developed a conceptual model that distinguishes three roles that can be used to identify nursing outcomes:

- Independent roles - or "the activities of assessment, decision making, intervention and follow up that define the nursing process... [and] the autonomous action based on scientific rationale that is executed to benefit the patient" (p. 60).

- Dependent roles - or roles that involve carrying out medical orders or treatments

- Interdependent roles - where either the nurse is dependent upon other health professionals to carry out activities or functions or others are dependent on the nurse.

I believe these concepts may provide a basis for explaining practice nurse work. There is clear differentiation of nursing activities and the relationship to patient care and the general practice team. However, as the authors point out 
there are number of variables that need to be taken into account such as staffing levels, environment and communication practices. Therefore, the framework provides a conceptual basis only and the detail of activity would need to be specifically aligned to nursing work in general practice and to PHC.

\section{Knowing the community}

Another aspect made discernible in these narratives is that of living in the community and having the knowledge about the community and the kinds of issues that confront people. In addition having the ability and knowledge to negotiate systems and make care more available for people either inside or outside the community is crucial.

As Ervin (2002) states, "listening provides the opportunity for the nurse to bear witness to the everyday experiences of people" (p. 60). Traditionally community nursing has not been clearly linked to practice nursing, perhaps because the practice nurse is constrained by a 'clinic,' however these narratives suggest that practice nurses have a knowledge and understanding of community that is not always acknowledged or accessed either inside or outside the general practice context. Dunphy, Winland-Brown, Porter, and Thomas (2007) connect knowing and unknowing to caring competence, enabling the nurse to be open to all possibilities and therefore able to connect people to services whilst understanding the context, history and nuances of the local community. Therefore, connections and conversations become more meaningful by the knowing, sincerity and availability.

There is an opportunity for nurses to be acknowledged in this role and supported to expand knowledge and networking in ways that are more formal and recognized as an important aspect of nursing work. For example, this might involve going outside the 'clinic' to build relationships and clarify community services. This is particularly relevant to the PHC principles that emphasise the improvement of community relationships and the prevention of fragmentation through developing community capacity. 


\section{Working collegially}

Collegial relationships were seen as a source of satisfaction and support. Three of the five narratives illustrate close collegial relationships with one GP and the nurses were dependent upon that person to support their decisions in their day-today work. Two narratives illustrate the diversity of general practice where one works in a clinical and managerial role and the other as a sole nurse who spent a large part of the day as the only health practitioner on site. There is a tension in both these instances - combining administrative, clinical and a managerial role is not always easy.

There is no doubt that teamwork is a key part of improving health outcomes however, professionals often have different understandings of this concept. There is nevertheless a clear relationship to the autonomous practice of nurses and agreed understandings of teamwork (Xyrichis \& Ream, 2007). In addition to achieve effective teamwork requires both open communication and a commitment to learning and sharing together (McCallin, 2005; Pullon \& McKinlay, 2007). Illustrated within the narratives defined aspects of team practice are visible, however interactions tend to be informal and based on the familiarity of long-term working relationships.

All participants valued the complementary community nursing roles, referred patients, and asked advice of these nurses, but they were not perceived as part of a team of community nurses. In addition, they did not feel that nursing colleagues really understood the nature and extent of their work. They believed that although practice nursing had changed over the years there was still a perception that practice nurses were still 'handmaidens'. There remains an opportunity for nursing teams to exist across traditional boundaries and diverse contexts therefore strengthening responses to population need.

Buresh and Gordon (2000) suggest that in order to "convey the content of nursing, nurses must describe the complexity of the care they give and the clinical judgements they use" (p. 71), as nursing is not simply following the orders of the doctors. There is a challenge in this statement for nurses to claim 
their own voice and agency and act to describe more fully the work that they do in general practice. I believe that claiming agency could be achieved by articulating nursing knowledge as propositional, craft and personal (Titchen \& McGinley, 2004). Utilising this framework could assist in developing professional visibility. As Richardson, Adrandt, Dahlgren and Higgs (2004) advocate:

"Knowing in professional practice is a process that is fed, energized and driven by individuals in their work, but its momentum can be maintained only through making it explicit: through talking about it and refecting on it with others in professional debate...We all have a responsibility to share our thoughts and reasons for our actions in practice" (p. 208).

Similarly, Besner (2006) strongly believes that in order to advance the PHC agenda nursing must make practice quality and capability explicit particularly as patterns of collaborative practice are established.

In conclusion, preserving the presence of nursing in any busy environment is never easy and nursing has always struggled to define its professional difference and capability often in the face of medical dominance (Dunphy, et., al 2007). As Pearson (2003) suggests more than ever understanding of nursing is lacking. If access to consistent primary health care is a key part of improving health outcomes, particularly for those who are traditionally underserved (Hartley, 2002, McMurray, 2003) I believe general practice needs to be clear about the role of nursing in the PHC environment and recognise the broad dimension of practice that does not necessarily equate with specific feefor-service. As recruitment and retention are of considerable concern in the global health environment, the preservation of a skilled and connected nursing workforce is vital.

\section{Implications for practice, education and research}

This study highlights nursing work in general practice and as such provides a representation of the breadth of skill and knowledge required by those entering into general practice context. An emphasis on understanding the community, 
relational practice and understanding how to work in teams are important concepts. In addition, learning to articulate the detail of day-to-day practice and reflecting on this should be emphasised through professional portfolios and publication. Again as Besner (2006) notes, if nurses are to affect change and influence policy they need a "solid understanding of what is their unique role in contributing to attainment of desired health outcomes in the populations they serve" ( $\mathrm{p} 284$ ). One way of doing this may be engaging with practice nurses and assisting in a process of articulating their scope of practice so that the entire general practice team acknowledges their expertise and knowledge.

Strategies and policies that recognise nurses' strengths and interests in the context of the GP team are one aspect that may support retention strategies. By valuing the expertise and knowledge that the practice nurse has of community and individuals, the implementation of new models of care and consolidation of existing practice may become more sustainable. In addition shared governance is an important concept as nurses often have insights into ways to manage workload that is useful to day-to-day operation of general practice. The narratives in this research illustrate that these elements are part of practice nurses' day-to-day practice. Therefore where management emphasises and encourages "interaction, learning and innovation" (Holden, 2005, p. 656) there is opportunity for improved adaptability and problem solving in conjunction with new models of care into general practice.

One solution to increasing the voice and visibility of nursing in general practice may be to consider the use of complex adaptive systems theory. There is no doubt that general practice is a complex environment due to political, population and individual factors and will continue to be so as government strategy directs more responsibility for health care solutions and improved outcomes to this context. Complex adaptive systems (CAS) theory offers explanations that highlight the potential for multiple agents (nurses, doctors and administration staff) to work together. Instead of traditional management systems that are hierarchical in nature CAS suggests that interdependence 
creates adaptability. Of note underpinning complex adaptive systems theory in healthcare is the principle that connecting relationships, creativity, involvement, self-organisation and collaboration are required to improve patient care (Rowe \& Hogarth, 2005). Relevant to both practice teams and nursing management, CAS "integrates easily into nursing values and beliefs" (Penprase \& Norris, p. 127), by acknowledging unpredictability and complexity and supporting nurses to adapt to change in self-determining ways.

In education, the challenge is to articulate to nursing students the value of primary health care and working in general practice. Nursing education at undergraduate level that emphasises relational practice, the development of community knowledge and the improvement of skills to work alongside other health professionals cannot be underestimated. Identifying a clear career pathway, emphasising the possibilities of job satisfaction and the opportunities to work collegially whilst developing a broad knowledge and skill base are additionally important. At postgraduate and professional development level, the articulation of knowledge and nursing activities, interprofessional practice skill and learning must is vital to ensure that general practice teams can work more effectively. Consideration of the tensions between the service and business philosophies needs to be addressed, alongside provision of accessible primary health care for populations.

Opportunity to engage in nurse-led research is required to support the conceptualisation and development of nursing work general practice. This is particularly important as new models of nursing such as mobile nursing or nurse-led clinics are advanced. Furthermore, in order to support innovation, analysis of existing work practices, contexts and outcomes is important. The possibility of further narrative research with other general practice team members would develop the daily aspects of work to a greater degree. Action research with general practice nursing teams could have an impact on empowering nurses to articulate and develop their practice more explicitly in the future. 


\section{Limitations}

There are a number of limitations to this research as referred to in the methodology chapter. To reiterate, these narratives are representative of practice nurse experience and perspective along with my own subjective voice as no actual observation of practice nurse work took place. Perspectives of GPs and patients were not sought; however, employing a narrative research methodology could illustrate the experience and viewpoints of these groups. Secondly as the process of participant selection limits any ability to generalise, this study is concerned with the experience and perspective of the participants rather than extrapolating the findings to large populations (Gillis \& Jackson, 2002). Ultimately, the aim of this interpretative narrative research project is to bring 'voice' to a specific group of nurses.

One critique of narrative in nursing suggests that the relational aspects of nursing are over emphasised and technical aspects underplayed when in fact the two go hand in hand. In addition, nursing narratives have been used to develop frameworks of expertise against which practice constructions are made (Nelson \& McGillion, 2004). It is not an intention of this work to make judgements of expertise or comparisons of practice, but view the constructed narratives within the individual, temporal and experiential contexts that they are placed, therefore reflecting the methodology. In addition, the focus on subjectivity within this work is displayed clearly by the 'supportive voice'.

As I had positioned myself as a practice nurse and primary health care nurse the participants anticipated that I would 'know' what they were talking about (and as I did understand), the transcripts are full of sentences that end with 'you know'. Therefore, the construction and addition of detail, using footnotes became part of the interpretation and construction of the narrative.

On reflection, if I were engaged in future narrative research I would conduct two pilot interviews beforehand to refine the questioning process and plan the project with more time to conduct interviews. I would also plan for a second 
or third interview with each participant - this would be an opportunity to capture additional data and clarify meaning within experience.

In conclusion using a narrative methodology to bring a qualitative view of practice nursing is an original concept in this context. Illuminating the day-today experience of practice nurses brings clarity to previously unseen aspects of the role. With the development of PHOs and the challenges of PHC the mandate to work differently using a population health approach continues to be progressed. Simply changing employment structures will not necessarily enable change to occur and, there is a chance that the very collegial relationships that benefit patients and support nurses to expand and / or advance practice will be undermined. For my own role, a focus on supporting nurses to conceptualise and articulate their daily work more clearly is important, particularly in response to the myriad of changes that affect healthcare. Alongside this role, there is an opportunity to strengthen caring competence and reflective practice through professional development and by relating nursing work more clearly to the underlying premises of PHC.

It is possible that if practice nurses remain silent about their work they will lose their ability to be professionally determining, particularly as new models of health progress. The question is - how can the art and science of nursing be retained and valued in general practice in ways that are more explicit and visible? The production of nursing practice detail in narrative form is one way to engage with other nurses, health professionals and the public.

This study set out to make practice nursing visible and in doing so bring value and worth to this rich and diverse role. It has made explicit the daily experiences of five nurses who work with a range of individuals and communities using a methodology not previously employed in this sphere. The value of nurse-patient relationships and provision of continuity of care whilst managing daily complexity and unpredictability is clarified. The importance of autonomous and specialty practice are identified as crucial to job satisfaction and necessary to respond to diverse populations. The presence 
of nursing in general practice is integral to the day-to-day management, therefore the voice of nursing must be heard and involved in every respect as new models of care and systems develop and progress. 


\section{References}

Abrandt Dahlgren, M., Richardson, B., \& Sjostrom, B. (2004). Professions as communities of practice. In Developing practice knowledge for health professionals. London: Butterworth-Heinemann.

Allen, D. (2007). What do you do at work? Profession-building and doing nursing. International nursing review, 54(1), 41- 48.

Atkinson, P., \& Delmont, S. (2005). Analytic perspectives In N. Denzin, K \& Y. Lincoln (Eds.), The Sage Handbook of Qualitative Research (3rd ed.). Thousand Oaks, CA: Sage.

Bamberg, M. (2007). Introductory remarks. In M. Bamberg (Ed.), Narrative - State of the Art (pp. 1-5). Amsterdam: John Benjamins.

Barrett, R., \& Barrett, P. (2004). Back to the future? Reflections on past reforms and future prosects for health services in New Zealand GeoJournal, 59(2), 137-147.

Barton, S. (2004). Narrative inquiry: locating Aboriginal epistemology in a relational methodology. Journal of Advanced nursing 45(5), 519-526.

Branson, C., Badger, B., \& Dobbs, F. (2003). Patient satisfaction with skill mix in primary care: A review of the literature. Primary Health Care Research and Development, 4, 329-339.

Besner, J. (2004). Nurse's call in advancing primary health care: A call to action. Primary Health Care Research and Development, 5, 351-356.

Besner, J. (2006). Optimizing nursing scope of practice within primary health context: Linking role accountabilities to health outcomes Primary Health Care Research and Development, 7, 284-290.

Beverly, J. (2005). Testimonio, Subalternity and narrative authority In N. Denzin \& Y. Lincoln (Eds.), The Handbook of Qualitative Research (3rd ed., pp. 547-557). Thousand Oaks, CA: Sage Publications.

Bowers, R., \& Moore, K. (1997). Bakhtin, nursing narratives, and dialogical consciousness. Advances in Nursing Science, 19(3), 70-78.

Boyd, M. (2004). Expanding the role of practice nurses - care management of high risk chronically ill. Practice Nurse, 4(1), 8-9.

Breen, A., Carr, E., Mann, E., \& Crossen-White, H. (2004). Acute back pain management in primary care: A qualitative pilot study of the feasibility of a nurse-led service in general practice. Journal of Nursing Management 12, 201209.

Brooks, F. (2004). The spirit of 'health for all': The shape of primary health care, past, present and future. Primary Health Care Research and Development, 5, 281-28. 
Buresh, B., \& Gordon, S. (2000). From Silence to voice: What nurses know and must communicate to the public. Ottawa: Canadian Nurses Association.

Buresh, B., \& Gordon, S. (2006). From silence to voice: What nurses must know and communicate to the public (2nd ed.). New York: Cornell University Press.

Burns, N., \& Grove, S., K. (2005). The Practice of Nursing Research: Conduct, Critique and Utilization (5th ed.). St Louis: Elsevier Saunders.

Caldow, J., Bond, C., Ryan, M., Campbell, N., San Miguel, F., Kiger, A., et al. (2006). Treatment of minor illness in primary care: A national survey of patient satisfaction, attitudes and preferences regarding a wider nursing role. Health Expectations, 10, 30-45.

Carson, A., \& Fairburn, G. (2002). The whole story: Towards an ethical research methodology. Nurse Researcher, 10(1), 15-29.

Chase, S., E. (2005). Narrative Inquiry: Multiple Lenses, Approaches, Voices In N. Denzin \& Y. Lincoln (Eds.). The Sage Handbook of Qualitative Research (3rd ed.). Thousand Oaks, CA: Sage.

Clandinin, D. J., \& Connelly, F. M. (2000). Narrative Inquiry: Experience and Story in Qualitative Research San Francisco: Jossey-Bass Inc.

Clandinin, D. J., \& Huber, J. (2002). Narrative Inquiry: Toward understanding life's artistry Curriculum Inquiry 32(2), 161-169.

Clark, S. (2007). Research on nurse staffing and its outcomes: The challenges and risks of grasping at shadows. In S. Nelson \& S. Gordon (Eds.). The complexities of care. New York Cornell University Press.

Clendon, J., \& White, G. (2001). The feasibility of a nurse practitioner-led primary health care clinic in a school setting: A community needs analysis. Journal of Advanced Nursing, 34(20), 171-178.

Clissold, C. M. (2006). How discourses stifle the primary health care strategy's intent to reduce health inequalities. Unpublished thesis. Victoria University.

College of Nurses Aotearoa (2001). The Nursing Answer to Inequalities in Primary Health Care, Position Paper by the Primary Health Care Network, College of Nurses Aotearoa New Zealand.

Crampton, P. (1999). Policies for General Practice. In P. Davis \& T. Ashton (Eds.), Health and Public Policy in New Zealand (pp. 201-218). Auckland: Oxford University Press.

Crampton, P., Sutton, F., \& Foley, J. (2002). Capitation funding of primary care services: Principles and prospects. Journal of the New Zealand Medical Association 115(1155). 
Crotty, M. (1998), The Foundations of Social Research: Meaning and perspective $n$ the research process. Crows Nest, NSW: Allen \& Unwin.

Darbyshire, P. (2006). Heroines, hookers and harridans: Exploring popular images and representations of nurses and nursing In J. Daly, S. Speedy \& D. Jackson (Eds.), Contexts of Nursing (2nd ed.). Marrickville, NSW: Elsevier.

Davis, P., Lightfoot, R., Finn, E., Lay-Yee, R., Gribben, B., \& McAvoy, B. (1999). Practice Nurses in the Waikato, 1991-1992: What was their patient mix and pattern of care? [Electronic Version]. New Zealand Family Physician. Retrieved 27/10/07.

Dew, K., \& Kirkman, A. (2002). Sociology of Health in New Zealand. Auckland: Oxford University Press.

Docherty, B. (1996). Nursing in General Practice: A New Zealand Perspective. Christchurch: Caxton Press.

Dunphy, L., Winland-Brown, J., Porter, B., \& Thomas, D. (2007). Primary care in the twenty-first century: A circle of caring In L. Dunphy, J. Winland-Brown, B. Porter \& D. Thomas (Eds.), Primary Care: The Art and Science of Advanced Practice Nursing (2nd ed.). Philadelphia: F.A. Davis.

Edgecombe, G. (2006). Healthy communities: Is there a role for nurses / nursing? In J. Daly, S. Speedy \& D. Jackson (Eds.), Contexts of Nursing (2nd ed.). Marrickville, NSW: Elsevier.

Elliot, J. (2005). Using narrative in social research: Qualitative and Quantitative Approaches. London: Sage.

Ervin, N., E. (2002). Advanced Community Nursing Practice New Jersey: Prentice Hall.

Evans, C., Drennan, V., \& Roberts, J. (2005). Practice nurses and older people: A case management approach to care. Journal of Advanced Nursing, 51(4), 343-352.

Eve, R., Hodgkin, P., Quinney, D., \& Waller, J. (2000). What do practice nurses do? A study of roles, responsibilities and patterns of work. The Centre for Innovation in Primary Care. Retrieved from www.innovate.org.uk on 12/08/2007.

Expert Advisory Group on Primary health Care Nursing (2003). Investing in health: Te oranga tangata: A framework for investing in primary health care in New Zealand. Wellington: Ministry of Health.

Faithfull, S. \& Hunt, G. (2005). Exploring nursing values in the development of a nurseled service. Nursing Ethics, 12(5), 440-452.

Fontana, A., \& Frey, J., H. (2003). The interview: From neutral stance to political involvement In N. Denzin, K \& Y. Lincoln (Eds.), The Sage Handbook of Qualitative Research (3rd ed.). Thousand Oaks, CA: Sage. 
Gibson, T., \& Heartfield. (2005). Mentoring for nurses in general practice: An Australian study. Journal of Interprofessional care, 19(1), 52-62.

Gillis, A., \& Jackson, W. (2002). Research for Nurses: Methods and Interpretation Philadelphia F.A Davis Company.

Goodman, C. (2000). Integrated nursing teams: In whose interests. Primary Health Care Research and Development, 1, 207-215.

Grant, B., \& Giddings, L. (2002). Making sense of methodologies: A paradigm framework for novice researchers. Contemporary Nurse, 13(1), 10-28.

Green, A. (2004). Have health sector reforms strengthened PHC in developing countries? Primary Health Care Research and Development, 5, 289-295.

Guba, E., \& Lincoln, Y. (2003). Paradigmatic controversies, contradictions and emerging confluences In N. Denzin, K \& Y. Lincoln (Eds.), The Sage Handbook of Qualitative Research. Thousand Oaks, CA: Sage.

Haggerty, J., Reid, R., Freeman, G., Starfield, B., Adair, C., \& McKendry, R. (2003). Continuity of care: A multidisciplinary view. British Medical Journal, 327(7425), 1219 - 1221.

Halcomb, E., Davidson, P., Daly, J., Yallop., \& Tofler, G. (2004). Australian nurses in general practice based heart failure management: Implications for innovative collaborative practice. European Journal of Cardiovascular Nursing, 3, 135-147.

Halcomb, E., Patterson, E., \& Davidson, P. (2006). Evolution of practice nursing in Australia. Journal of Advanced Nursing, 55(3), 376-390.

Hardy, S., Garbett, R., Titchen, A., \& Manley, K. (2002). Exploring nursing expertise: Nurses talk nursing. Nursing Inquiry, 9(3), 196-202.

Harrison, S., Dowswell, G., \& Wright, J. (2002). Practice nurses and clinical guidelines in a changing primary care context: An empirical study Journal of Advanced Nursing, 39(3), 299-307.

Hartley, L. A. (2002). Examination of primary care characteristics in a community based clinic. Journal of Nursing Scholarship, 34(4), 377-382.

Heath, I. (2004) Complexity and uncertainly as the links between science and the humanities in general practice. New Zealand family Physician, 31(3), 136-138.

Hegney, D, Eley, R, Buikstra, E, Rees, S \& Patterson, E. (2006). Consumers' level of comfort with an advanced practice role for registered nurses in general practice: A Queensland, Australia Study. Australian Journal of Primary Health, 12(3), 4451 .

Hodgson, P. (2006). Primary health - low fees are good but what's next? Paper presented at the Dunedin School of Medicine. 
Holden, L. (2005). Complex adaptive systems: Complex analysis. Journal of Advanced Nursing, 52(6), 651-657.

Holstein, J., A., \& Gubrium, J., F (Eds.). (2003). Inside Interviewing: New lenses, new concerns. Thousand Oaks: Sage.

Hughes, F. (2006). Nurses at the forefront of innovation. International Nursing Review, $53,94-101$.

Hughes, J., \& Sharrock, W. (1997). The Philosophy of Social Research (3rd ed.). Harlow, UK: Addison Wesley Longman Ltd.

Irvine, D., Sidani, S., \& McGillis, L. (1998). Linking outcomes to nurses roles' in health care. Nursing Economics, 16(2), 58-87.

Jamieson, R. (2002). Practice Nurses in primary health care: "Don't just watch this space!" The Practice Nurse 2(4), 22.

Jonsdottir, H., Litchfield, M., \& Pharris, M. (2004). The relational core of nursing practice as partnership. Journal of Advanced Nursing, 47(3), 241-250.

Kelly, T. \& Howie, L. (2007) Working with stories in narrative research: Procedures used in narrative analysis. International Journal of Mental Health Nursing, 16, 136-144.

Kendall, S., \& Bryar, R. (2003). The question of community nursing research. Primary Health Care Research and Development, 4, 95-96.

Kenealy, T., Arroll, B., Kenealy, H., Docherty, B., Scott, D., Scragg, R., et al. (2004). Diabetes care: Practice nurse roles, attitudes and concerns. Journal of Advanced Nursing, 48(1), 68-75.

Koch, T. (1996). Implementation of a hermeneutic inquiry in nursing: Philosophy, rigour and representation. Journal of Advanced Nursing, 24, 174-184.

Koch, T. (1998). Story telling: is it really research? Journal of Advanced Nursing, 28(6), 1182-1190.

Koch, T. (1999). An interpretative research process: Revisiting phenomenological and hermeneutical approaches. Nurse Researcher, 6(3), 20-34.

Koch, T., \& Harrington, A. (1998). Reconceptualizing rigour: The case for reflexivity. Journal of Advanced Nursing, 28(4), 882-890.

Lather, P. (1991). Getting Smart: Feminist research and pedagogy with/in the postmodern. London: Routledge

Lawler, J. (1997). The body in Nursing. Melbourne: Churchill Livingstone. 
Lewis, R. (2001 ). Nurse-led Primary Care, Learning from PMS pilots. London: Kings Fund.

Liamputtong, P., \& Ezzy, D. (2005). Qualitative Research Methods (2nd ed.). Melbourne: Oxford.

Lindsay, G. (2006). Experiencing nursing education research: Narrative inquiry and interpretative phenomenology. Nurse Researcher, 13(4), 30-47.

Lindsay, G., \& Smith, F. (2003). Narrative inquiry in a nursing practicum. Nursing Inquiry, 10(2), 121-129.

Love, T. (2004). Complexity - not as complicated as it looks. New Zealand Family Physician, 31(3), 139-141.

MacIntosh, J., \& McCormack, D. (2001). Partnerships identified within primary health care literature. International Journal of Nursing Studies 38, 547-555.

Magnussen, L., Ehiri, J., \& Jolly, P. (2004). Comprehensive versus selective primary health care. Lessons from global health policy. Health Affairs, 23(3), 167-176.

May, C., \& Flemming, C. (1997). The professional imagination: Narrative and symbolic boundaries between medicine and nursing. Journal of Advanced Nursing, 25, 1094-1100.

Macdonald, J. (2004). Primary health care: A global overview. Primary Health Care Research and Development, 5, 284-288.

McCallin, A. (2005). Interprofessional practice: Learning how to collaborate. Contemporary Nurse, 20(1), 28-37.

McEvoy, P. (2001). Interviewing colleagues: Addressing the issues of perspective, inquiry and representation Nurse Researcher, 9(2), 49-58.

McKinlay, E. (2006). New Zealand practice nursing in the third millennium. New Zealand Family Physician, 33(3), 162-168.

McMurray, A. (2003). Community health and wellness: A sociological approach. Marrickville, NSW: Mosby.

McMurray, A. (2007). Leadership in primary health care. Contemporary Nurse, 26(1), 30-36.

McQueen, L. \& Zimmerman, L. (2006). Using interpretative narrative research in interdisciplinary research projects. Journal of Nursing Education, 45(11), 475478.

Ministry of Health. (2003). Primary health Care and Community Nursing Workforce Survey - 2001. Wellington: Author. 
Minto, R. (2004). Practice Nurses as providers. To be or not to be? The Practice Nurse $4(2), 11$.

Minto, R. (2006). The future of practice nursing. New Zealand Family Physician 33(3), $169-172$.

Nelson, S \& McGillion, M. (2004) Expertise or performance? Questioning the rhetoric of contemporary narrative use in nursing. Journal of Advanced Nursing, 47(6), 631-638.

Pascoe, T., Foley, E., Hutchinson, R., Watts, I., Whitecross, L., \& Snowden, T. (2005). The changing face of nurses in Australian general practice. Australian Journal of Advanced Nursing, 23(1), 44-50.

Patterson, E., Del Mar, C., \& Najman, J. (1999). A descriptive study of nurses employed by general practitioners in South-East Queensland. Australian Journal of Advanced Nursing 17(2), 13-20.

Patterson, E., Muenchberger, H., \& Kendall, E. (2007). The role of practice nurses in coordinated care of people with chronic care and complex conditions. Australian Health Review, 31(2), 231-238.

Pearson, A. (2003). Multidisciplinary nursing: Re-thinking role boundaries. Journal of Clinical Nursing, 12, 625-629.

Pellico, L., \& Chin, P. (2007). Narrative criticism: A systematic approach to the analysis of story Journal of Holistic Nursing 25(1), 58-65.

Penprase, B \& Norris, D. (2005). What nurse leaders should know about complex adaptive systems theory. Nursing Leadership Forum, 9(3), 127-132.

Phillips, C., \& Dwan, K., Pearce, C., Hall, S., Porrit, J., Yates, R., et al. (2007). Time to talk, time to see: Changing microeconomies of professional practice among nurses and doctors in Australian general practice. Contemporary Nurse 26, 136144.

PHC Nurses' validated. (2006). Kai Tiaki Nursing New Zealand, 12(7), 8.

Plummer, K. (2001). Documents of life 2: an invitation to a critical humanism. London: Sage.

Polkinghorne, D. (1988). Narrative Knowing and the Human Sciences. Albany: State University of New York Press.

Price K, (2007) Nurses in general practice settings. Roles and responsibilities.

Contemporary Nurse, 26(1), 7-14. 
Pritchard, A., \& Kendrick, D. (2001). Practice nurse and health visitor management of acute minor illness in a general practice. Journal of Advanced Nursing, 36(4), $556-562$.

Pullon, S., Cornford, E., McLeod. D., de Silva, K. \& Simpson, C. (2005). Workplace factors: The key to successful and sustained continuation of a general practicebased smoking cessation programme. Australian Journal of Primary Health, 11(1), 55-62.

Pullon, S., \& McKinlay, E. (2007). Interprofessional learning: The solution to collaborative practice in primary care. New Zealand Family Physician, 34(6), 404-408.

O'Connor, T. (2003). Practice nurses feel undervalued. Kai Tiaki Nursing New Zealand, $9(2), 25$.

Rapley, T. J. (2001). The (art)fullness of open ended interviewing. Qualitative Research, 1(3), 303-323.

Richardson, B., Abrandt Dahlgren, M., \& Higgs, J. (2004). Practice epistemology: implications for education, practice and research. In A. Titchen, J. Higgs \& M. Abrandt Dahlgren (Eds.), Developing practice knowledge for health professionals. London: Butterworth.

Roberts, S. J. (2000). Development of a positive professional identity: Liberating oneself from the oppressor within. Advances in Nursing Science, 22(4), 71-82.

Rosen, R., \& Mountford, L. (2002). Developing and supporting extended nursing roles: The challenges of NHS walk-in centres. Journal of Advanced Nursing, 39(3), 241-248.

Ross, J. (1999). The development of the advanced role of rural nurses in New Zealand. Australian Journal of Rural Health, 7, 253-257.

Rosser, W., \& Schultz, K. (2007). Promoting continuity of care should be integral to any health care system. Canadian Medical Association Journal 177(11), 1385-1386.

Rowe, A., \& Hogarth, A. (2005). Use of adaptive systems metaphor to achieve professional and organisational change. Journal of Advanced Nursing, 51(4), 396-405.

Sandelowski, M. (1994). We are the stories we tell: Narrative knowing in nursing practice. Journal of Holistic Nursing, 12(1), 23-33.

Seibold, C. (2000). Qualitative research from a feminist perspective in the postmodern era: Methodological, ethical and reflexive concerns. Nursing Inquiry, 7(3), 147155 . 
Shum, C., Humphreys, A., Wheeler, D., Cochrane, M.-A., Skoda, S., \& Clement, S. (2000). Nurse management of patients with minor illness in general practice: Multicentre randomised controlled trial [Electronic Version]. British Medical Journal. (International edition), 320, 1038-1046. Retrieved 07/11/2005.

Shuy, R., W. (2003). In-person versus telephone interviewing. In J. Holstein, A. \& J. Gubrium (Eds.), Inside interviewing: New lenses, new concerns. Thousand Oaks: Sage.

Sibbald, B. (2003). Keynote address: Nurses in general practice: An evolution in primary care. Paper presented at the General practice and primary health care research conference: primary health care research - evolution or revolution.

Sibbald, B., Laurant, M., G, \& Reeves, D. (2006). Advanced nurse roles in UK primary care. Medical Journal of Australia, 185(1), 10-12.

Smith, M. J., \& Liehr, P. (2005). Story theory: Advancing nursing practice scholarship. Holistic Nurse Practitioner 19(6), 272-276.

Smith, P. (2006 ). Practice nurse plan welcomed. Australian Doctor, 4-5.

Spilsbury, K., \& Meyer, J. (2001). Defining the nursing contribution to patient outcomes: Lessons from a review of the literature examining nursing outcomes, skill mix and changing roles. Journal of Clinical Nursing 10, 3-14.

Stake, R. (2003). Case studies. In N. Denzin \& Y. Lincoln (Eds.), Strategies of qualitative inquiry (2nd ed.). Thousand Oaks: Sage.

Stark S., Warne, T., \& Street, C. (2002). Practice nurses and integrated care examined. Primary Health Care Research and Development, 3, 11-21.

Stevenson, B. (2006). Is a nurse worth it? Australian Doctor, 48-49.

Titchen, A., \& McGinley, M. (2004). Blending self-knowledge and professional knowledge in person-centered care In J. Higgs, B. Richardson \& M. Abrandt Dahlgren (Eds.), Developing practice knowledge for health professionals. London: Butterworth-Heinemann.

Thomas Hegyvary, S. (2007). An Agenda for Nursing as a Means to Improve Health Journal of Nursing Scholarship, 103-104.

Todd, C., Howlett, M., MacKay, M., \& Lawson, B. (2007). Family practice / Primary Health Care Nurses in Nova Scotia. The Canadian Nurse, 103(6), 23-27.

Walsh, N., Roe, B., \& Huntington, J. (2003). Delivering a different kind of primary care? Nurses working in personal medical pilots. Journal of Clinical Nursing, 12, 333340 .

Williams, M. (2003). Making sense of social research. London: Sage. 
Williams, A., \& Sibbald, B. (1999). Changing roles and identities in primary health care: Exploring a culture of uncertainty. Journal of Advanced Nursing, 20(3), 737-745.

Willis, E., Condon, J. \& Litt, J. (2000). Working relationships between practice nurses and general practitioners in Australia: A critical analysis. Nursing Inquiry, 7, 239-247.

Wood, P.J., \& Giddings, L.S. (2003). Revealing storied lives - Life story narrative inquiry in nursing and midwifery: An interview with Rose McEldowney. Nursing Praxis in New Zealand, 19(2), 4-17.

WHO. (1978). Declaration of Alma-Ata. Paper presented at the International Conference on Primary Health Care, Alma-Ata, USSR.

WHO. (1986). Ottawa Charter for Health Promotion. Paper presented at the First International Conference on Health Promotion Ottawa, Canada.

WHO. (1997). The Jakarta Declaration on Health Promotion in the 21st Century. Paper presented at the Fourth International Conference on Health Promotion, Jakarta.

Xyrichis, A., \& Ream, E. (2007). Teamwork: A concept analysis. Journal of Advanced Nursing, 61(2), 232-241. 


\section{Appendix One}

TE WHARE WĀNANGA O TE ŪPOKO O TE IKA A MĀUI

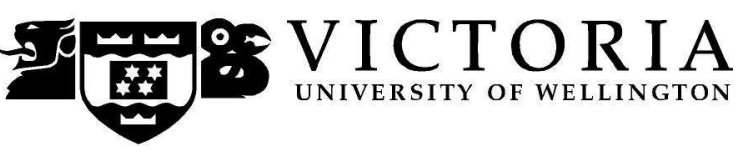

MEMORANDUM

Phone $\quad 0-4-4635676$

Fax 0-4-4635209

Email_Allison.kirkman@vuw.ac.nz

\begin{tabular}{l|l}
\hline TO & Katrina Fyers \\
\hline COPY TO & Professor Jo Ann Walton \\
\hline FROM & Dr Allison Kirkman, Convener, Human Ethics Committee \\
\hline
\end{tabular}

\begin{tabular}{l|l}
\hline DATE & August 13, 2007 \\
\hline PAGES & 1 \\
\hline
\end{tabular}

\begin{tabular}{l|l}
\hline SUBJECT & $\begin{array}{l}\text { Ethics Approval: No 117/2007, Illuminating the stories that } \\
\text { practice nurses tell of their day-to-day experience in general } \\
\text { practice. }\end{array}$ \\
\hline
\end{tabular}

Thank you for your application for ethical approval, which has now been considered by the Standing Committee of the Human Ethics Committee.

Your application has been approved and this approval continues until 28 February 2008.

If your data collection is not completed by this date you should apply to the Human

Ethics Committee for an extension to this approval.

Best wishes with the research.

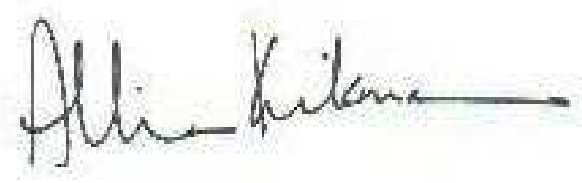

Allison Kirkman

Convener 


\section{Appendix Two}

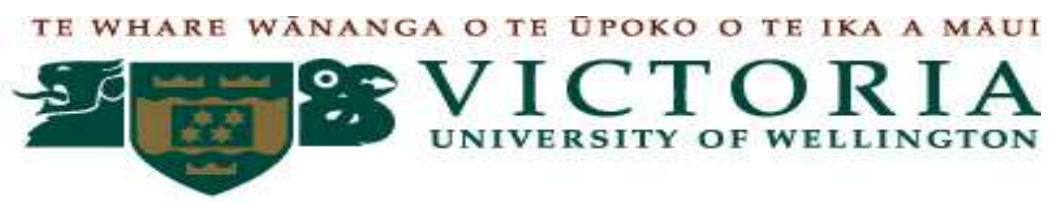

\section{INFORMATION SHEET}

Illuminating the stories that practices nurses tell of their day-to-day experience in general practice

I am a Master of Arts (Applied) in Nursing student at Victoria University of Wellington, and as part of this degree I am undertaking a research project leading to a thesis. My nursing experience encompasses a range of primary health care nursing roles with the most recent being practice nursing.

My project involves interviewing 6-8 practice nurses and asking them to share moments and stories of their day-to-day experience whilst nursing in general practice.

The intent of this project is to share these collective perspectives with wider audiences in order to give visibility (clarity), voice and value to the work that practice nurses engage in.

I am inviting practice nurses who work in low cost access rural and urban practices to participate in this study and share stories of their nursing practice. Participation will involve 1 or 2 interviews of approximately $1-1 \frac{1}{2}$ hour duration and will be conducted by myself. An audiotape will be used to record the interview and I may also take written notes.

These tapes and notes will be kept secure at all times and no one will read the transcripts or notes or listen to the tapes except myself and my thesis supervisor Professor Jo Ann Walton from Victoria University, Wellington. The final responses 
will be reported in a way that it will be impossible for you to be identified in any way although small quotes may be included using a pseudonym.

Participants may choose to withdraw at any time during the process without question. Please just let me know if you wish to do this.

I will send copies of the transcripts to you for your feedback if you wish either by secure mail or email. The thesis will be submitted for marking and then deposited in the University library. It is intended that one or more articles will be submitted for publication in scholarly journals.

If you wish a summary of the main points and any recommendations from the report will be available to you at the conclusion of the report.

Tapes and notes will be destroyed at the end of the research. Transcripts will be destroyed one year after completion of the research.

If you have any questions or would like to receive further information please contact me on

0275719939 or by email katrina.fyers@ clear.net.nz or my supervisor,

Professor Jo Ann Walton, at the Graduate School of Nursing, Midwifery and Health at Victoria University, PO Box 600, Wellington, phone 04463135 (email jo.walton@vuw.ac.nz).

This project has been approved by the Victoria University Human Ethics Committee: ref approval number 117 / 2007

Katrina Fyers 


\section{Appendix Three}

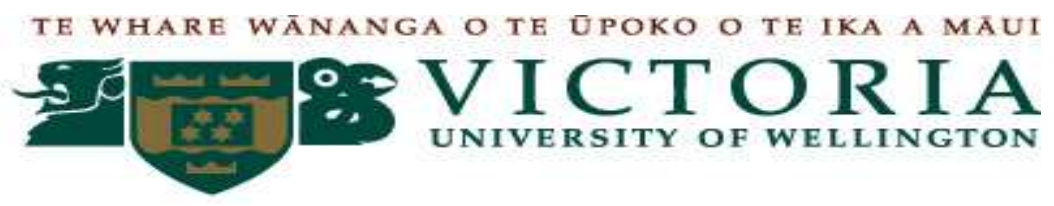

\section{CONSENT TO PARTICIPATION IN RESEARCH}

Illuminating the stories and experiences of practice nurses in general practice

\section{$\underline{\text { Researcher: Katrina Fyers }}$}

I have been given and understand an explanation of the research project. I have had an opportunity to ask questions and have them answered to my satisfaction.

I understand that I may withdraw myself and any information provided by me from this research project at any stage without question.

I understand that the recordings, notes and transcripts of my interview will be kept in a secure place, that no one other than the researcher; her supervisor and a confidential typist who will assist with transcribing will have access to them.

I understand that the tapes will be electronically wiped at the end of the research and the transcripts destroyed after one year.

I understand that any information provided by me will be unidentifiable and that my name will be kept confidential to the researcher.

I understand that I am not obliged by this consent process to agree to a second interview.

I would like to review all my transcripts. Yes No

I understand alterations to my transcript will be made if I request. 
I would like to receive a summary of the research findings when the research is completed. Yes No

I agree to take part in this research.

Signed:

Dated:

Address for draft or report 


\section{Appendix Four}

\section{Confidentiality Agreement for Transcriber \\ of a Research study}

I have read the information sheet outlining this study. I have discussed with the researcher the nature of the research and have had any questions that I have had answered to my satisfaction. My role as the research transcriber has been outlined to me by the researcher.

At all times the research information (tapes and transcripts) will be inaccessible to other persons. The researcher has assured me that she will debrief me following transcribing to address any issues that transcribing bring up for me.

Most importantly, I understand and agree to keep the information I hear and type in the course of transcribing confidential to the researcher and myself.

Full Name:

Signature:

Date:

Researcher's Signature:

Date: 


\section{Appendix Five}

\section{Prompts for interviews}

How did you come to be working as a practice nurse

Tell me/ give an account / describe a typical day in your nursing practice?

- Tell me about the moments of fulfilment or satisfaction or excitement that are significant or stand out from others in your day-to-day practice? For example that is those times when you feel that you have made a difference, had a good outcome, and had an extraordinary day that gave you the impetus to come to work the next day.

Are you able to share a story that might illustrate these moments ...

Moments of challenge /dilemmas or uneasiness that may be significant or stand out from others? A story....

- Circumstances that might be significant or that surround these moments? Thoughts about feelings that you had, any reflections, reminders, connections with other events... 